Open Access

\title{
Does a transition in education equate to a transition in practice? Thai stakeholder's perceptions of the introduction of the Doctor of Pharmacy programme
}

Teeraporn Chanakit ${ }^{1 *}$, Bee Yean Low ${ }^{2}$, Payom Wongpoowarak ${ }^{3}$, Summana Moolasarn ${ }^{4}$ and Claire Anderson ${ }^{1}$

\begin{abstract}
Background: Pharmacy education and pharmacy practice are facing remarkable changes following new scientific discoveries, evolving patient needs and the requirements of advanced pharmacy competency for practices. Many countries are introducing or undertaking major transformations in pharmacy education. The Thai pharmacy curriculum has been changed from a 5-year BPharm and a 6-year PharmD to only a 6-year PharmD programme. Curriculum change processes usually involve stakeholders, including both internal and external educational institutions, at all levels. This study aims to understand the experiences and perceptions of stakeholders regarding the transition to an all-PharmD programme in Thailand.
\end{abstract}

Methods: Semi-structured interviews were conducted in Thailand with 130 stakeholders (e.g., policy makers, pharmacy experts, educators, health care providers, patients, students and parents) from August-October 2013. The interviews were audio recorded, transcribed verbatim and analysed using an inductive thematic analysis.

Results: Three main themes were derived from the findings: 1. influences on curriculum change (e.g., the needs of pharmacists to provide better patient care, the US-Thai consortium for the development of pharmacy education); 2 . perceived benefits (e.g., improve pharmacy competencies from generalists to specialists, ready to work after graduation, providing a high quality of patient care); and 3. concerns (e.g., the higher costs of study for a longer period of time, the mismatch between the pharmacy graduates' competency and the job market's needs, insufficient preceptors and training sites, lack of practical experience of the faculty members and issues related to the separate licenses that are necessary due to the difference in the graduates' specialties).

Conclusions: This is the first study to highlight the issues surrounding the transition to the 6-year PharmD programme in Thailand, which was initiated due to the need for higher levels of competency among the nation's pharmacists. The transition was influenced by many factors. Many participants perceived benefits from the new pharmacy curriculum. However, some participants were concerned about this transition. Although most of the respondents accepted the need to go forward to the 6-year PharmD programme, designing an effective curriculum, providing a sufficient number of qualified PharmD preceptors, determining certain competencies of pharmacists in different practices and monitoring the quality of pharmacy education still need to be addressed during this transitional stage of pharmacy education in Thailand.

Keywords: Stakeholders, Perceptions, Transition, PharmD programme, Preceptors, Workforce, Thailand, A qualitative study

\footnotetext{
* Correspondence: paxtc2@nottingham.ac.uk

'School of Pharmacy, University of Nottingham, Nottingham, UK

Full list of author information is available at the end of the article
} 


\section{Background}

Pharmacy education and pharmacy practice are facing remarkable changes following new scientific discoveries, evolving patient needs and the requirements for advanced pharmacy competency for current and future practices $[1,2]$. Therefore, many countries are introducing or undertaking major transformations in pharmacy education $[1,2]$. The World Health Organization (WHO), the United Nations Educational, Scientific and Cultural Organisation (UNESCO) and the International Pharmaceutical Federation Education Development Team (FIPEd) all aim to improve global pharmacy education and have developed a "needs-based education model" [1, 3-6]. The model stipulates that pharmacy education programmes must be designed to ensure that required competencies are achieved by all pharmacy graduates to deliver pharmacy services that meet the needs of national populations. Many countries have been upgrading their pharmacy degree programmes to the level of Doctor of Pharmacy (PharmD) [7-13]. However, literature exploring the adoption of such programmes in Asian countries is limited [14-16].

The initiation of modern pharmacy education in Thailand began in 1913 with a 3-year programme which extended to a 4-year programme in 1939 and then to a 5-year Bachelor in Pharmacy (BPharm) programme in 1957 [17-19]. In 1993, the US-Thai consortium for the development of pharmacy education in Thailand was established [19]. Thai pharmacy educators and pharmacy practitioners participated in this collaboration to develop the academic workforce that was needed. In 1999, the first of the Thai Doctor of Pharmacy (PharmD) programmes, which focused on patient care at the Faculty of Pharmaceutical Sciences, Naresuan University, was established $[18,20-22]$. The details of the history of all 6-year PharmD programmes in Thailand are shown in Fig. 1 [17, 23-36].

From 1990-2010, the majority of Faculties of Pharmacy in Thailand offered a 5-year BPharm programme. The 5-year programme was divided into three tracks: pharmaceutical sciences, pharmaceutical care and social and administrative pharmacy; this allowed students to achieve more professional specialisation [18, 23, 37]. However, the new pharmacy graduates and employers felt that the graduates were still inadequately trained and were not prepared for post-graduation practice [28, 38].

Similar to other countries that were changing to an Entry-Level PharmD (ELPD) programme [39-46], unified support for the transition to an all- PharmD programme was also limited in Thailand [39, 45]. Pramyothin et al. [30] found that while most experts from hospitals and consumer protection sectors agreed with a 6-year programme with special tracks, advanced practitioners from the community pharmacy and industry areas preferred a 5-year programme with special tracks. Wongpoowarak et al. [47] found that most pharmacy graduates and employers felt that a 6-year PharmD was needed for both tracks (pharmaceutical care and pharmaceutical sciences); they also reported that while academic staff had mixed views regarding the appropriate duration of a pharmacy

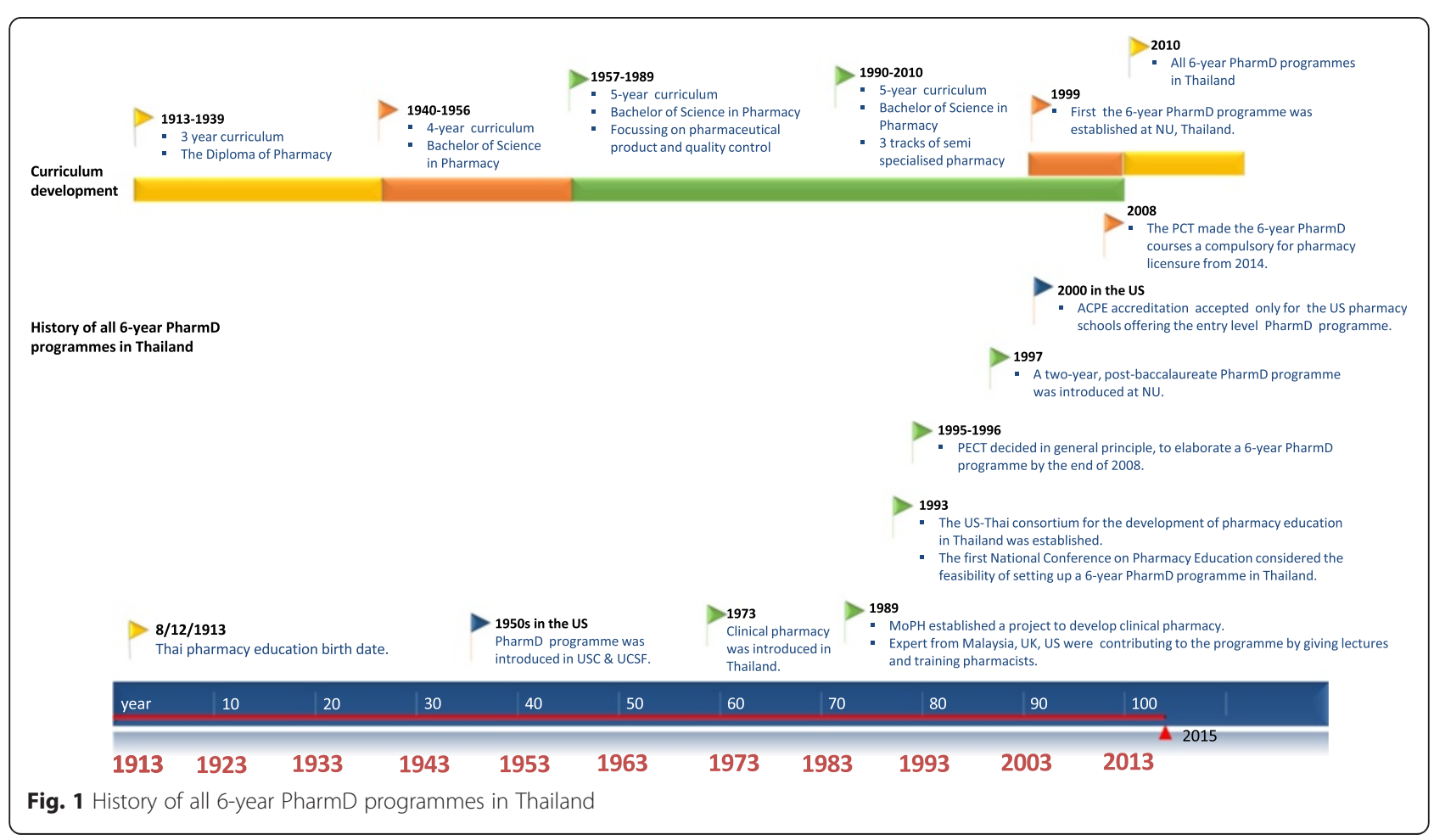


programme in pharmaceutical sciences, the majority (63\%) sided with 5 years as opposed $15 \%$ and $22 \%$ who preferred 4 years and 6 years, respectively. Another study which carried out a survey of pharmacists regarding curriculum changes found that most of the respondents did not agree that a 6-year programme would either decrease the pharmacy curriculum workload or improve the status of pharmacists to reach that of medicine and dentistry graduates (both also 6-year programmes). Most respondents agreed that the pharmacy curriculum should be producing generalists but that specialties should be studied in higher education. The majority of the respondents believed that the pharmacy curriculum should include both 5- and 6-year options, while about $20 \%$ of respondents believed that only one the 6-year programme should be offered [48, 49].

Thai policy makers believed that a complete transition to the 6-year PharmD would meet the needs of the stakeholders by changing pharmacy competencies from generalists to specialists, resolve the issue of curriculum overload for the high-credit 5-year BPharm programme, and produce equal educational standards and outcomes and for the pharmacy profession on a national level $[28,38]$. The Pharmacy Council of Thailand (PCT) announced that the 6-year PharmD programme would be compulsory for pharmacy licensure starting from year 2014 onwards; the BPharm programme was not offered after 2010 $[18,28,30,37]$. All new pharmacists have to graduate from pharmacy schools accredited by the Pharmacy Council, with a 6-year PharmD degree based on the new 6-year curriculum, a move designed to provide a more comprehensive curriculum and in-depth knowledge and skills in each specific pharmacy area [17, 18, 37, 50]. The US PharmD programme, which focuses on patient care, has been adjusted to meet the context of the Thai health system. The new PharmD curriculum is divided into two tracks, a Pharmaceutical Care-PharmD (PC-PD) programme and an Industrial Pharmacy (formerly Pharmaceutical Sciences)-PharmD (IP-PD) programme $[23,37,51-53]$. It is still under discussion as to whether another track, Social and Administrative Pharmacy (SAP), should either be independent or included in the other two tracks $[18,23]$. Pharmacy students in some faculties will select their specialty upon admission; in other faculties, students select their speciality programmes in the fourth year of the PharmD [37].

The transition has been implemented by a collaboration among regulatory bodies (e.g., PCT and government) and educational institutions [28]. However, debates and questions have been put forth on social networks about the need for a change to an all-PharmD programme in Thailand $[48,49]$; among the questions asked were: 'How would an all-PharmD programme produce graduates to meet the needs of various areas of pharmacy practices in
Thailand'? 'How to incorporate the diverse competencies of two specialised areas (PC-PD and IP-PD) into one professional license?' [18, 22, 30, 48]. Additionally, the limited resources and capacities of academic and training institutions in developing countries that are changing to a PharmD programme have been discussed $[5,54]$.

Stakeholders are an important aspect of the "needsbased model" comprised by FIPEd's Global Quality Assurance Framework because it is the stakeholders who dictate local or national needs $[2,55]$. For example, regulatory bodies, such as government and the Pharmacy Council, are responsible for pharmacy practice. They have the duty to protect the wellbeing of the public by assuring that the pharmacy workforce receives appropriate education and training to deliver a standard quality of services [2]. Curriculum change involves and affects many stakeholders, including both internal and external educational institutions (e.g., students, faculty members, staff members, administrators, employers, employees, patients and the public) at different levels, different roles and also different expectations [2, 55-58]. As such, exploring the stakeholders' perspectives and experiences regarding this transition is crucial. There has been very little evidence, to date, of such attempts in Thailand. Qualitative research can provide meaning and understanding and is ideally suited to explore a little researched area [59, 60]. Therefore, this paper reports on a qualitative study which was aimed to understand the experiences and perceptions of stakeholders regarding the transition to an all-PharmD programme in Thailand.

\section{Methods}

This study was granted ethical approval from the Faculty of Sciences, University of Nottingham and the ethics authorities in Thailand (the Research Ethics Committee of Ubon Ratchathani University and the Research Ethics Committee of Buddhachinaraj Hospital). Semi-structured interviews were conducted with 130 stakeholders in the Thai language during 1 Aug - 20 Oct, 2013.

Triangulated data were collected from different type of stakeholder categories via interviews across four different regions (e.g., Central, North, North-East, and South) to check and establish validity [61-63] and also include subgroups of each stakeholder category to further maximise sample variation [62, 64] (e.g. both administrators and non-administrators from educational institutions were targeted). Stakeholders groups included policy makers, pharmacy experts or representatives of the pharmacy profession's associations (e.g., public and private hospital pharmacy, community pharmacy, industrial pharmacy, public health and consumer protection, marketing pharmacy), educators (e.g., public and private university), practicing pharmacists from different settings (e.g., tertiary hospital, community hospital, community pharmacy, private 
hospital, industrial pharmacy, consumer protection, pharmacy marketing, research and development), health care providers (doctors, nurses, pharmacy technicians), patients, students and their parents as well as members of the general population. Participants included those involved in the quality assurance of pharmacy education according to the FIP definition [2]. Consensus among the main researchers (TC, CA, PW) was reached with regards to the selection process and sampling of participants. Table 1 lists the inclusion criteria.

Stakeholders who met the inclusion criteria and provided their consent for their interview data being included in a $\mathrm{PhD}$ thesis and publications [65] were recruited and interviewed using an interview guide (see Table 2). All participants were sent a participant information sheet explaining the study to them $[59,65]$. The interview guide was developed based on both the purpose of this study and a literature review. Pilot interviews with two academic staff members, two pharmacists, one nurse, one doctor, one member of the general population and two students were conducted to refine the interview strategy. The pilot interviews were included in the data analysis. Recruitment was conducted by purposive sampling and snowball sampling. Sampling and data collection was guided by emerging themes and continued until the point of data saturation that was established when the interviews did not yield any new or emerging themes [66] and the depth and extent of data collection and data analysis seemed sufficient to allow the researcher to tell a reasonable story $[67,68]$. The saturation was reached with varying numbers of participant from each sub-group of stakeholders. The depth and extent of data collection depended on participants' roles and involvement in pharmacy education; for example, saturation was reached with 20 academic members from three specialised area (e.g. pharmaceutical care, pharmaceutical sciences and social and administration pharmacy) and different type of PharmD programmes offered (e.g. PC-PD, IP-PD), with 5 doctors and 5 nurses who have different length of experience of working with PharmD pharmacists, with 10 policy makers who had different roles from the Pharmacy Council of Thailand and the Pharmacy Education Consortium of Thailand, and with 7 students from public and private universities. However, additional 1-2 participants from each subgroup of stakeholder were interviewed to confirm the saturation of themes.

The interviews lasted between $45-60 \mathrm{~min}$. All interviews were audio recorded with informed consent. The interviews had two sections, an introduction and personal background section (e.g., age, education, career, area of expertise, year of current work experience) and questions about their past and current experiences regarding the transition to an all-PharmD programme. Characteristics of the interviewees are given in Table 3. TC, a $\mathrm{PhD}$ research student has been a university lecturer in clinical pharmacy area at Ubon Ratchathani University, Thailand, for the last ten years and has observed the changes in pharmacy education; she has not been involved in influencing the policy of the all-PharmD programme. TC interviewed the participants in the setting of their choice (usually their workplace). 124 interviews were conducted face-to-face, five via telephone, and one was a Skype interview. PY and SM are university associate professors in Thailand. PY had been involved the transition period as a deputy dean of an academic affair and now is a policy maker of the PCT. SM has not been involved in influencing the policy of the all-PharmD programme. BL and CA are academic supervisors of TC who has not been involved in the transition of an all-PharmD programme in Thailand.

Audio recordings were transcribed verbatim in Thai and were checked twice for accuracy with the recordings by TC and one Thai pharmacist [69]. Transcripts were sent back to the interviewees for them to read or modify the transcript if necessary [59, 70]. However, the majority of participants chose not to check the transcripts. The transcripts were checked and confirmed the correctness by ten requested interviewees [62]. Thai transcripts were translated to English to comply with the required audit trail [71] by a Thai researcher (TC), who is a PhD student in the UK. The audit trail is an essential part of rigorous qualitative study that will able to track how the data were analysed and how themes were generated through interviews and interpreted to assess the trustworthiness of the research [72]. Additionally, it was essential that the transcripts be translated to English as CA, a non-Thai researcher and a senior qualitative researcher was directly involved in the analysis and coding processes [73]. Meaningbased translation [74] from Thai to English was performed by TC and had forward-blind backward translations process [74] to check the correctness of the translation. Twenty English transcripts were checked against the Thai transcripts by TC and a bilingual Thai-English pharmacy academic researcher. Two translators reached consensus regarding the English translation. Then, convenience blind backward translations [74, 75] of English transcripts into Thai were undertaken for 13 of the 130 transcripts (10\%) by the fluent Thai-English bilingual speaker. This process was performed to validate the translations and ensure no loss of conceptual equivalence had taken place [76].

English transcripts were then analysed thematically using NVivo qualitative data analysis software (QSR International Pty Ltd., Version 10, 2012) [77]. This study used an inductive (data-driven with themes emerging directly from the data) thematic analysis approach [78] and was influenced by the principle of grounded theory $[59,66,79]$ (e.g., the general explanation or theory development generated or "grounded" in data from the views of participants who have 
Table 1 The inclusion criteria and the selection of participants $[2,65-75]$

\begin{tabular}{llllll}
\hline Stakeholder group Central & North North-East & South & $\begin{array}{c}\text { Total } \\
\text { in pharmacy education }\end{array}$ & $\begin{array}{l}\text { Roles and importance } \\
\text { in pethod of }\end{array}$ & Selection and recruitment
\end{tabular}

1. Policy makers/regulatory

bodies $(n=10)$

-The Pharmacy Council

of Thailand (PCT) is the

regulatory body for

pharmacists in Thailand

Consortium of Thailand

(PECT) has seventeen

pharmacy educational

institution members

across Thailand.

2. Pharmacy experts $(n=13)$

-Pharmacy experts or

representatives of professional

pharmacy associations in

Thailand

-Hospital pharmacy

(from both public and

private hospitals)

-Community pharmacy

-Industrial pharmacy
-The PCT has a role to protect and maintain the wellbeing of the public by maintaining standards and public trust in pharmacy (e.g., setting standards for conduct, ethics, and competency, accrediting pharmacy degree programmes and pharmacy educational institutions, processing licensure examination and registration). They must assure that pharmacists receive appropriate education and training and are competent to deliver services.

PECT aims to promote the

advancement of pharmacy

education, support the

pharmacy professional practice,

protect common interests among

members, facilitate pharmacy student

activities, and collaborative work with

other professional organisations

(e.g., PCT and Thai pharmacy

associations).

-PECT prepared a government

scholarship to support faculty

development and by 1993 PECT

signed the first bilateral collaboration

between US and Thai pharmacy

schools, the US-Thai Consortium for

the Development of Pharmacy

Education in Thailand. This consortium

opened opportunities for Thai

academic members and students

to be trained and study in the US.

Pharmacy experts and pharmacy

practitioners are able to determine the

competencies required to deliver the

services that meet the needs of

employers and customers.

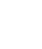

-Policy makers, who had or still have

Interview roles in curriculum change ever since

the issue of an all-PharmD was raised in

1993, were invited by email or letter and

telephone at least one month prior to

the interview date.

-Eleven policy makers were invited to

participate; one policy maker from the

Pharmacy Council did not respond

within the timeframe of the study.

-Pharmacy experts or representatives of professional associations were identified primarily through the public websites of their organisations, selected by

researchers, and invited by email and

telephone at least one month prior to the interview date.

-Experts or representatives from

pharmacy associations from five areas in

Thailand (e.g., the Association of Hospital 
Table 1 The inclusion criteria and the selection of participants [2, 65-75] (Continued)

-Public health and consumer 3

protection

-Marketing pharmacy

(1)

0

0

3

3

1

\section{Academic staff $(n=25)$}

-Dean

-Deputy dean (academic)

professional development)

Academic staff

-Pharmaceutical care area

-Industrial pharmacy/pharmaceutical

sciences area

-Social and administrative

pharmacy area

$\begin{array}{lllll}\mathrm{U}^{\mathrm{a}} 1 \mathrm{U} 2 & \mathrm{U} 3 & \mathrm{U} 4 & \mathrm{U} 5 & 5 \\ 2 & 1 & 1 & 1 & 4 \\ 1 & 1 & 1 & 1 & \\ & & & & \\ & 2 & 2 & 1 & 6 \\ 1 & 1 & 1 & 1 & 5 \\ 2 & & & & \\ 1 & 1 & 2 & 1 & 5\end{array}$

-Faculties of pharmacy and academic members have responsibilities in terms of the quality of education and value of investment in higher education for students and families. Faculty

members committed to lifelong learning in their specialty and continuous improvement of their teaching skills,

devote sufficient time to teaching along with research, administrative or academic services (e.g., clinical roles) and also have a duty to develop learning opportunities and encourage pharmacy students to

participate. Faculty staff have

influence on promoting learning environments, demonstrate professional responsibility, encourage and assist their students to assume responsibility for their learning and express concern regarding student development.

Students and their families invest finances and time to obtain a

pharmacy degree and aim to learn within a pharmacy curriculum designed to prepare them for the profession. They have the right to expect that the PharmD programme has been sharmD programme has been sufficiently evaluated and meets the
standards outlined by the PCT which
Pharmacy (Thailand), the Community

Pharmacy Association (Thailand), the Thai

Industrial Pharmacist Association, the

Marketing Pharmacy Association Thailand) and the Thai Food and Drug Administration (FDA) as well as law and consumer protection area and experts from the Pharmaceutica Association of Thailand, who were current practitioners, well known and were accepted by pharmacists in their professional practice areas, were invited.

-Sixteen experts or representatives of pharmacy organisations were invited to participate in this study; three experts (1 from a hospital, 1 from industry and 1 from marketing) did not respond within the timeframe of the study. $n=13$ )

-The criteria to select the universities were based on the region of the university, type of ownership, type of programme, year established and feasibility of study. -Five universities (four public and one private university) were selected and invited and letter requesting permission to conduct research with each faculty was sent to the dean. All faculty granted permission to conduct this research.

-Deans, deputy deans of academic affair or deans in pharmacy professional development and faculty members were invited.

-The details of the five faculties are as follows:

-U1 (public) used to offer BPharm and then changed to PC-PD \& IP-PD

.U2 (private) used to offer BPharm and then changed to PC-PD \& IP-PD

U3 (public) offering PC-PD

.U4 (public) used to offer BPharm and then changed to PC-PD

-U5 (public) used to offer BPharm and PC-PD and then changed to PC-PD \& IP-PD

-Inclusion criteria were students who were currently studying in the final year of a 6-year PharmD programme because they had experience with the new 6-year PharmD programme or the students who were studying in the $5^{\text {th }}$ year if their faculties did not have $6^{\text {th }}$ year students during this study period (Aug-Oct 2013). Participation was voluntary.
-Interview - Skype $^{b}$

-Telephone

interview ${ }^{b}$

-Interview -Telephone

interview 
Table 1 The inclusion criteria and the selection of participants [2, 65-75] (Continued)

5. Parents $(n=4)$

6. Pharmacists $(n=30)$

-Tertiary hospital

(Three pharmacists are the

administrators)

-Community hospital

-Community pharmacy

-Private hospital

(One pharmacists is an

administrator)

-Industrial

-Public health and consumer

protection

-Marketing

-Research and development

7. Health care providers

$(n=18)$

-Physicians

(Three physicians are the

administrators)

-Nurses(Two nurses are the

administrators)

-Pharmacy technicians should able to prepare them for a pharmacy professional career. Students should expect that the pharmacy curriculum is timely, practical and for successful professional practice.

Parents play an important role in

students' university life (e.g., parental support in terms of facilitating persona social, and academic development and finances). They are concerned about the accreditation of institutions for the mature development of their children and preparing their children for the profession.

Pharmacy experts and pharmacy practitioners are able to determine the competencies required to deliver services that meet the needs of the fervices that methe needs of the care providers and public).

0
provide essential knowledge and skills

-Students were invited to participate by a researcher at the cafeteria or library of their faculty at least 1 day prior to an interview date. possibility of contact their parents to

The pharmacy profession has embraced a patient-focused role and works closely with other health care professionals. Health with other healch care professionals. Health care providers opinions are very impor curriculum as multidisciplinary education curriculum as multidisciplinary education, especially in terms of advanced practice experience or clinical clerkships, during which pharmacy students are exposed to other health care providers and learn how to become a member of a team after they graduate. In addition, health care provider opinions will explain how other health profession view the role of pharmacists in health care teams.

-Pharmacists work with patients to ensure that they receive the best outcomes from their medications. -They are the final users of pharmacy practitioners. Patients' opinions are important to improve the quality of pharmacy services and enhance interview. The nurses were requested to
-Inclusion criterion was a parent of the student who was currently studying in the final year of a 6-year PharmD programme. -Researcher asked the students about the participate in this study.

-Most parents lived in other provinces.

Therefore parents were invited and

interviewed by the researcher via telephone.

Health care providers (doctors, nurses, pharmacists and pharmacy technicians), students and their parents were contacted directly at their workplace at least 1 day pror directly at their workplace at least 1 day prior to an interview date. However, the patients (at two hospitals) and general population
(at local supermarkets in urban and rural areas) were asked for their participation on the actual interview date, due to employing convenience sampling.

-Telephone

interview

-Interview

Health care providers (doctors, nurses, pharmacists and pharmacy technicians) were invited directly at their workplace at least 1 day prior to an interview date.

-In-patients who had received pharmaceutical services on the medical wards from PharmD pharmacists within the last two weeks prior to identify and invite patients who were willing to participate. Interviews took place bed-side on patients' wards with respect for the privacy of
-Interview

-Interview 
Table 1 The inclusion criteria and the selection of participants [2, 65-75] (Continued)

communication and expectations between patients and pharmacists, increase the quality of pharmacy education and also improve the accountability and transparency of health care delivered to patients.

9. General population $(n=7)$

-Taxi driver

-Merchant

-Government officer

- Non-governmental

organisation (NGO)

0
1
1
1

0
-The roles of pharmacists and pharmacy education have changed. The perception of the general public regarding this change is important; for example, how they perceive the new role of

pharmacists, the knowledge and skills required of pharmacists to provide better services for them, and whether they trust the advice that they may receive from pharmacists.

-Their opinions will help to determine how the pharmacy profession and education can improve public

understanding and perceptions of pharmacists in the future.

patients' interviews.

-Out-patients at chronic disease clinics

(e.g., DM clinic, oncology clinic and warfarin

from Pharm

months. To minimise the selection bias from

pharmacists, the patients had been selected by

pharmacists, the patients had been selected by

visit day. If patients had pharreening on the

visit day. If patients had pharmacy counselling

in the last three months, then the researcher

asked the pharmacist to invite patients to

participate during the lag interval, while those

patients were waiting to see their doctor or

waiting for their prescription. Interviews took

place in private counselling rooms.

General population at a local supermarket in Bangkok (capital city), Ubon Ratchathani and Songkhla province (outside the capital city). 
Table 2 Interview guide

\begin{tabular}{|c|c|}
\hline & Questions \\
\hline General/background information & $\begin{array}{l}\text { Personal information: education, work experience, age, area of expertise, year of current work } \\
\text { experience. }\end{array}$ \\
\hline $\begin{array}{l}\text { Feelings and attitude towards a 6-year } \\
\text { PharmD programme }\end{array}$ & How do you feel about the all-PharmD policy in Thailand? \\
\hline Impact of curriculum change & $\begin{array}{l}\text { What will be the impact of the curriculum change on education, pharmacy practice and the health } \\
\text { care system? }\end{array}$ \\
\hline \multicolumn{2}{|l|}{$\begin{array}{l}\text { Policy makers, pharmacy experts } \\
\text { and academic staff }\end{array}$} \\
\hline -Historical series or process & Please tell me about the history of PharmD curriculum development in Thailand. \\
\hline \multirow[t]{4}{*}{-Reason for changing } & Why do Thai pharmacy education have to change to a 6-year PharmD curriculum? \\
\hline & Who/which other organisations support this policy and why? \\
\hline & How does the PharmD curriculum value/suit the context of Thailand? \\
\hline & (Probes: health care system, quality of patient care, pharmacists' roles, law and regulation) \\
\hline \multirow[t]{2}{*}{-Involvement } & Please tell me about your role and responsibility in changing the curriculum policy. \\
\hline & Please tell me about the influence or motivation (in general/for your contribution) for this change. \\
\hline \multirow[t]{7}{*}{-Process of changing policy } & $\begin{array}{l}\text { What are the differences between the new PharmD programme and previous programme (e.g., } \\
\text { BPharm, a traditional PharmD programme)? }\end{array}$ \\
\hline & How will the new curriculum change? \\
\hline & Manner of enacting of change: policy/real practice \\
\hline & Process in which you are involved \\
\hline & Readiness, preparedness for this change \\
\hline & Key learning, key enablers, significant challenges/ barriers \\
\hline & What do you need in terms of support? \\
\hline \multirow[t]{6}{*}{ Pharmacy students } & Motivating factors to study pharmacy \\
\hline & Choice of faculty of pharmacy \\
\hline & Perceptions of the 6-year PharmD programme \\
\hline & Experience as a final year student in the new PharmD programme \\
\hline & Impact of curriculum change (on student and family/ pharmacy profession/ career image) \\
\hline & Future career ambitions and views of career development \\
\hline \multirow[t]{4}{*}{ Parents } & Perceptions of the 6-year PharmD programme \\
\hline & Parental support for their children's education \\
\hline & $\begin{array}{l}\text { Experience as a parent of a PharmD student Impact of curriculum change (on student and family/ } \\
\text { pharmacy profession/ career image) }\end{array}$ \\
\hline & Future career ambitions and views of career development \\
\hline \multirow[t]{7}{*}{ Employers } & Perceptions of the 6-year PharmD programme \\
\hline & General expectation of PharmD graduates \\
\hline & Differences in competencies/duties between BPharm and PharmD pharmacists? \\
\hline & Satisfaction with BPharm and PharmD pharmacists in terms of competencies and pharmacy services \\
\hline & Expectations from pharmacists' roles \\
\hline & Expectations from pharmacy education institutions/pharmacy curriculum \\
\hline & Impact of curriculum change (on student and family/ pharmacy profession/ career image) \\
\hline \multirow[t]{5}{*}{ Pharmacists } & Perceptions of an all-PharmD programme \\
\hline & What are the differences in terms of about competencies/duties between BPharm \\
\hline & and PharmD pharmacists? \\
\hline & Expectations of into the new curriculum and real work situation \\
\hline & How do you perceive about PharmD pharmacists in your workplace settings? \\
\hline
\end{tabular}


Table 2 Interview guide (Continued)

Health care providers

Patients/ general public

Closing questions
Are there any differences in competencies between PharmD and BPharm pharmacists?

What makes a PharmD pharmacist different from a BPharm pharmacist?

What is the barrier to move from the traditional pharmacy to advanced pharmacy practice?

How to across the barrier?

What do you expect from a PharmD pharmacist?

Preceptor roles

Specific questions for PharmD pharmacists

How often/ how many days a week do you intervene regarding patients' medications?

How do PharmD pharmacists add value to patient care?

How do you think your patients think about you?

Are there any differences in competencies between PharmD and BPharm pharmacists?

How often do you contact a PharmD pharmacist regarding patients' medications?

How do you perceive PharmD pharmacists in your workplace settings?

Are there any differences in competencies between PharmD and BPharm pharmacists?

Are you satisfies with the pharmaceutical care services from PharmD pharmacists?

What is the barrier to move from traditional pharmacy to advanced pharmacy practice?

What do you want to suggest to improve PharmD services?

Perceptions of pharmacy curriculum change to a 6-year PharmD programme

Expectations of the new curriculum and pharmacy practices in real workplace situation

Suggestions about multidisciplinary education

Please explain the services that you receive from your pharmacists?

How do you think about your pharmacist? Are you satisfied with the pharmaceutical care services?

What do you want to suggest about improving pharmacy services?

Do you know how long the pharmacy programme is?

How do you think that pharmacy education changes with a 6-year programme?

Is there anything you would like to add about an all-PharmD programme?

Is there anything that concerns you about the interviews or that you would like to ask me before we finish?

Would you like to check your transcript after the interview? experience with the process; while the researcher collects data, they begin analysis and go back to the field to collect more information until data saturation is achieved, used constant comparison analysis and theoretical sampling to maximise the variation of participants) [62, 64]. However, this study aimed to understand and develop an explanation regarding this transition, which differs from pure grounded theory as grounded theory aims to build the theory [79].

The data analysis was undertaken with the following steps [80]:

1. The analysis began after the first two interviews for each stakeholder group were transcribed and continued during and after data collection.

2. The first two English transcripts from each stakeholder group were read and re-read to gain an understanding of the interviewees' perceptions and experiences $[59,78]$ by two researchers (TC, CA).
They independently read transcripts carefully lineby-line, noted possible codes within the transcript hard copy, and then started to code and produce a coding structure.

3. The coding structure was revised and further developed [59]. The codes were compared and discussed by two authors (TC, CA) [62, 81-85].

4. The coding process was started again for all transcripts using the NVivo 10.0 software.

5. A constant comparative analysis (moving back and forth between the identification of similarities and differences among emerging categories) approach was taken; for example, new information that might add to the code was constantly compared with previous codes or categories or themes that it might fit, or it was determined whether a new code or category should be created. The emerging themes were 
Table 3 Descriptive characteristics of participants ( $n=130$ )

\begin{tabular}{|c|c|c|c|c|c|c|c|c|c|c|c|}
\hline Participants & $\begin{array}{l}\text { Policy } \\
\text { makers }\end{array}$ & $\begin{array}{l}\text { Pharmacy } \\
\text { Experts }\end{array}$ & Educators & $\begin{array}{l}\text { Pharmacy } \\
\text { students }\end{array}$ & Parents & Physicians & Nurses & Pharmacists & $\begin{array}{l}\text { Pharmacy } \\
\text { technicians }\end{array}$ & Patients & $\begin{array}{l}\text { General } \\
\text { public }\end{array}$ \\
\hline Number of participants & 10 & 13 & 25 & 9 & 4 & 7 & 6 & 30 & 5 & 14 & 7 \\
\hline \multicolumn{12}{|l|}{ Gender } \\
\hline Male & 7 & 7 & 13 & 4 & 1 & 5 & 0 & 7 & 1 & 4 & 4 \\
\hline Female & 3 & 6 & 12 & 5 & 3 & 2 & 6 & 23 & 4 & 10 & 3 \\
\hline \multicolumn{12}{|l|}{ Age group (years) } \\
\hline $20-30$ & 0 & 0 & 3 & 9 & 0 & 0 & 2 & 8 & 3 & 2 & 0 \\
\hline $31-40$ & 0 & 0 & 2 & 0 & 0 & 3 & 1 & 11 & 1 & 2 & 2 \\
\hline $41-50$ & 0 & 6 & 13 & 0 & 2 & 1 & 2 & 6 & 1 & 5 & 4 \\
\hline $51-60$ & 5 & 6 & 6 & 0 & 2 & 3 & 1 & 5 & 0 & 2 & 1 \\
\hline More than 60 & 5 & 1 & 1 & 0 & 0 & 0 & 0 & 0 & 0 & 3 & 0 \\
\hline \multicolumn{12}{|l|}{ Work experience (years) } \\
\hline less than 5 & 0 & 0 & 3 & 0 & N/A & 0 & 2 & 1 & 3 & N/A & N/A \\
\hline $5-10$ & 0 & 0 & 0 & 0 & N/A & 2 & 0 & 15 & 1 & N/A & N/A \\
\hline $11-15$ & 0 & 0 & 0 & 0 & N/A & 1 & 0 & 2 & 0 & N/A & N/A \\
\hline $16-20$ & 0 & 2 & 8 & 0 & N/A & 0 & 1 & 4 & 1 & N/A & N/A \\
\hline more than 20 & 10 & 11 & 14 & 0 & N/A & 4 & 3 & 8 & 0 & N/A & N/A \\
\hline \multicolumn{12}{|l|}{ Working area (years) } \\
\hline $\begin{array}{l}\text {-Hospital pharmacy } \\
\text { (tertiary care hospital, } \\
\text { public) }\end{array}$ & 1 & 3 & 0 & 0 & 0 & 4 & 3 & 11 & 3 & 0 & 0 \\
\hline $\begin{array}{l}\text {-Hospital pharmacy } \\
\text { (community hospital, } \\
\text { public) }\end{array}$ & 0 & 1 & 0 & 0 & 0 & 3 & 3 & 4 & 2 & 0 & 0 \\
\hline $\begin{array}{l}\text {-Hospital pharmacy } \\
\text { (private) }\end{array}$ & 0 & 1 & 0 & 0 & 0 & 0 & 0 & 2 & 0 & 0 & 0 \\
\hline -Community pharmacy & 0 & 3 & 0 & 0 & 0 & 0 & 0 & 5 & 0 & 0 & 0 \\
\hline -Industrial pharmacy & 1 & 2 & 0 & 0 & 0 & 0 & 0 & 2 & 0 & 0 & 0 \\
\hline $\begin{array}{l}\text {-Public health and } \\
\text { consumer protection }\end{array}$ & 1 & 2 & 0 & 0 & 0 & 0 & 0 & 2 & 0 & 0 & 0 \\
\hline -Marketing pharmacy & 0 & 1 & 0 & 0 & 0 & 0 & 0 & 2 & 0 & 0 & 0 \\
\hline $\begin{array}{l}\text {-Research and } \\
\text { development }\end{array}$ & 0 & 0 & 0 & 0 & 0 & 0 & 0 & 2 & 0 & 0 & 0 \\
\hline $\begin{array}{l}\text {-Academic (pharmaceutical } \\
\text { care) }\end{array}$ & 3 & 0 & 10 & 0 & 0 & 0 & 0 & 0 & 0 & 0 & 0 \\
\hline $\begin{array}{l}\text {-Academic (Pharmaceutical } \\
\text { technology }\end{array}$ & 4 & 0 & 10 & 0 & 0 & 0 & 0 & 0 & 0 & 0 & 0 \\
\hline $\begin{array}{l}\text {-Academic (Social and } \\
\text { administrative pharmacy) }\end{array}$ & 0 & 0 & 5 & 0 & 0 & 0 & 0 & 0 & 0 & 0 & 0 \\
\hline \multicolumn{12}{|l|}{ Highest education } \\
\hline \multicolumn{12}{|l|}{ 1. Physician } \\
\hline -Doctor of Medicine (MD) & 0 & 0 & 0 & 0 & 0 & 1 & 0 & 0 & 0 & 0 & 0 \\
\hline -MD, Diploma & 0 & 0 & 0 & 0 & 0 & 2 & 0 & 0 & 0 & 0 & 0 \\
\hline -MD, Specialist & 0 & 0 & 0 & 0 & 0 & 4 & 0 & 0 & 0 & 0 & 0 \\
\hline \multicolumn{12}{|l|}{ 2. Nurse } \\
\hline $\begin{array}{l}\text {-Bachelor of Nursing } \\
\text { Science }\end{array}$ & 0 & 0 & 0 & 0 & 0 & 0 & 4 & 0 & 0 & 0 & 0 \\
\hline -Master of Nursing Science & 0 & 0 & 0 & 0 & 0 & 0 & 2 & 0 & 0 & 0 & 0 \\
\hline
\end{tabular}


Table 3 Descriptive characteristics of participants $(n=130)$ (Continued)

\begin{tabular}{|c|c|c|c|c|c|c|c|c|c|c|c|}
\hline \multicolumn{12}{|l|}{ 3. Pharmacist } \\
\hline -BPharm & 0 & 2 & 0 & 0 & 0 & 0 & 0 & 11 & 0 & 0 & 0 \\
\hline -MPharm/MSC & 2 & 7 & 2 & 0 & 0 & 0 & 0 & 12 & 0 & 0 & 0 \\
\hline -PharmD & 0 & 0 & 0 & 0 & 0 & 0 & 0 & 7 & 0 & 0 & 0 \\
\hline$-\mathrm{PhD}$ & 8 & 3 & 17 & 0 & 0 & 0 & 0 & 0 & 0 & 0 & 0 \\
\hline $\begin{array}{l}\text {-PharmD, Pharmacy } \\
\text { residency }\end{array}$ & 0 & 0 & 3 & 0 & 0 & 0 & 0 & 0 & 0 & 0 & 0 \\
\hline -PharmD, Board specialties & 0 & 1 & 3 & 0 & 0 & 0 & 0 & 0 & 0 & 0 & 0 \\
\hline \multicolumn{12}{|l|}{ 4. Pharmacy technician } \\
\hline $\begin{array}{l}\text {-Diploma of public health } \\
\text { (Pharmacy Technique) }\end{array}$ & 0 & 0 & 0 & 0 & 0 & 0 & 0 & 0 & 4 & 0 & 0 \\
\hline -Bachelor & 0 & 0 & 0 & 0 & 0 & 0 & 0 & 0 & 1 & 0 & 0 \\
\hline \multicolumn{12}{|l|}{ 5. Patient, parent, public } \\
\hline $\begin{array}{l}\text {-Less than secondary } \\
\text { education }\end{array}$ & 0 & 0 & 0 & 0 & 0 & 0 & 0 & 0 & 0 & 5 & 1 \\
\hline $\begin{array}{l}\text {-Secondary education/ } \\
\text { vocational education }\end{array}$ & 0 & 0 & 0 & 9 & 2 & 0 & 0 & 0 & 0 & 5 & 2 \\
\hline -Bachelor & 0 & 0 & 0 & 0 & 2 & 0 & 0 & 0 & 0 & 4 & 3 \\
\hline -Higher than bachelor & 0 & 0 & 0 & 0 & 0 & 0 & 0 & 0 & 0 & 0 & 1 \\
\hline
\end{tabular}

coded and constantly compared and contrasted with other interviewees' transcripts [86].

6. To establish the reliability or the stability of responses to multiple coders of the dataset, this study used the intercoder agreement process. A draft code book was developed. It was aimed at determining the agreement of the coding in terms of code names and coded passages. TC and CA independently coded another two transcripts using a codebook and comparing codes. They considered the agreement of coding for these passages to be more than $80 \%$ of coding [62].

7. TC read through all transcripts repeatedly and coded them for analysis while a PhD supervisor (CA) checked and revised the coded text [73].

8. Thematic analysis was carried out using the "One Sheet of Paper, OSOP" mind map method to ensure that all the codes extracted within each theme were included and compared in the analysis [59]. This process aimed to find a story in the data, which involved reading through each section of the data and making notes on a single sheet of paper, and was used to ensure that all different issues were raised by the coded extracts, along with the relevant participant IDs [59, 87] (see Fig. 2). TA, $\mathrm{CA}$, and BY considered the development of broader themes from the codes.

Transcript coding (the process by which a qualitative analyst links specific codes to specific data segments or the process of organising data) involved four steps as follows:
1. In vivo coding or initial coding in-text indicates the coding of special terms of participants. In vivo codes help us to preserve interviewees' meaning regarding their perspectives or experiences in the coding itself [67]

2. Open coding (concepts/categories or free codes/free nodes in NVivo 10.0 software)

3. Axial coding (relationship between categories or tree code or tree nodes in NVivo 10.0 software)

4. Selective coding (core categories or higher level of concepts/themes) $[83,88]$

This study took the preliminary analyses consisting of themes back to six participants (e.g., two policy makers, two academic staff members, experts from the consumer protection area and industrial pharmacy), who would share their views of the analyses [62] to triangulate the data. They agreed on the accuracy and credibility of the findings. The findings and data from different sources [61-63] (e.g., government document, conference proceedings, unpublished reports, unpublished meeting minutes) were compared and contrasted; facts provided by the participants were confirmed.

\section{Results}

The findings revealed three major themes regarding stakeholders' perceptions towards the transition to the 6-year PharmD programme in Thailand: influences of an allPharmD programme in Thailand, perceived benefits and concerns regarding the transition to an all-PharmD programme. 
Table 4 Subthemes and supporting quotes within the theme "Influences of an all- PharmD policy" Key theme: Influences of an all- PharmD policy

Subthemes
The needs for pharmacists to provide a better
standard of pharmacy services

Concepts

Participants $^{a}$

Example of supporting quotes

Hospital pharmacists need in-depth
knowledge to provide a better of

patient care

Need more specialty due to

pharmacy graduates' competencies

from the previous pharmacy

PM9

9

\section{AC1_PSC_U1,}

AC14_SAP_U5,

AC22_D_U5, PM1, PM3,

programme (a 5-year BPharm) were PM5, PM8

too broad

Need higher competencies

AC3_PC_U4,

Pharmacists' roles involve in patient care

The global trend towards providing patient care services

The global trend of patient care services

AC8_PC_U4, PM1

PM1, PM7, PM8

"Hospital pharmacists should have the in-depth knowledge to

serve patients by doing more than dispensing medication,

"Policy makers believed that separate pharmacy specialty by have separate curriculum and training will meet the social need rather

than general pharmacist." (AC14_SAP_U5)

"They see the problem that our pharmacist was too generalised. Employers thought graduates did not have in-depth knowledge either in patient care or product focused." (AC22_D_U5)

"Another reason was regard to the 5-yearr programme which does not make us experts in medicines and patient care." (PM1)

"The reason is increasing competency which should have to separate two special tracts (PC-PD, IP-PD) with more practice training." (AC14_SAP_US)

"Now pharmacist's roles are more involvement in patient care." (AC8_PC_U4)

"We considered the direction at an international level and saw that the trend for developed countries was normally to adapt a practice role that emphasised patient care. This might be more suitable due to the PharmD programme giving us higher competencies as pharmacists." (PM1)

"Global trends are likely to come to specifically in

pharmaceutical care. This global trend needs a quality pharmacy the other way around, one more heavily weighted towards pharmaceutical care. Pharm care was requiring more profound training for new pharmacists to be ready to work." (PM7)

The Cooperation of four faculties of pharmacy and the Bureau of Health Service System

The Cooperation of four faculties of pharmacy and the Bureau of Health Development, Ministry of Public Health (MoPH) Service System Development, Ministry of Public Health (MoPH)

The US-Thai consortium for the development of A strong cooperative network of pharmacy education in Thailand

A stron, PECT, and the US-Thai consortium
the development of pharmacy education in Thailand

PM1, PM9

"There were agreed and jointed investment between four faculties of pharmacy and the Bureau of Health Service System Development, Ministry of Public Health (MoPH). It was an atmosphere of new learning." (PM1)

"The administrator of faculty of pharmacy had been visited the pharmacy school in the US.

They thought that they should have a clinical pharmacy focused programme which this future direction of pharmacist." (AC4_PC_U3)

AC3 PC U4, AC4 PC U3, "The PECT and Ministry of Public health were co-ordinate for US-Thai consortium. AC10 PS 4 W AC21_D_U5, AC22_D_U1, EXP13_HOS, PM1, PM2, PM10 were train from US." (AC10_PSC_U5)

"A 6-year PharmD programme was implemented by policy of the pharmacy council. Literally, I think it was influenced from US-Thai consortium which they (pharmacy council) had accepted concept from US quite a lot." (AC21_D_U5)

"It started from PECT since 1996-1997 that we have Thai-US consortium which is a subset of the project of pharmacy workforce development of MoPH. PECT thought that change to a 6 -year programme might be the way to develop the pharmacy profession in Thailand as in a developed country." (PM2) 
Table 4 Subthemes and supporting quotes within the theme "Influences of an all- PharmD policy" (Continued)

"The result of the consortium has had a great impact on Thai pharmacy education and the Thai pharmacy profession." (PM10)

"The Pharmacy Council stated that if we did not provide a 6-year PharmD curriculum, our students will not qualify to take the licensure examination. All faculties have to

The announcement of the the Pharmacy Council of Thailand (PCT)
The announcement of the the Pharmacy Council of Thailand (PCT)
AC21_D_U5, PM2, PM3, EXP12_COM, EXP13_HOS adapt their programmes to 6 years, no matter whether it is pharmaceutical sciences

or pharmaceutical care." (AC21 D U5)

"This policy was commenced as law by the Pharmacy Council." (PM2)

"If PCT did not announce as a regulation, this would never be ready, right? It was very confused at that time. We needed someone to make decisions for our future." (PM3)

"The intention of the PCT was good. They proposed to clarify the position of the pharmacy profession which might useful to our society and our profession." (EXP 13_HOS)

\section{Aabbreviation}

AC_PSC Academic member in pharmaceutical sciences area, $A C \_P C$ Academic member in pharmaceutical care area, $A C \_S A P$ Academic member in social and administrative pharmacy), $A C \_D$ Dean, EXP_HOS Expert in hospital pharmacy, EXP_COM community pharmacy, EXP_PSC Expert in industrial pharmacy, EXP PB Expert in public health and consumer protection, EXP_MP Expert in marketing pharmacy, $N$ Nurse, $P H \_H O S$ Hospital pharmacist, $P H_{-} C O M$ community pharmacist, $P H_{-} I P$ Industrial pharmacist, $P H_{-} P B$ Pharmacist in public health and consumer protection, $P H_{-} M P$ Pharmacist in marketing pharmacy, $P H_{-} R D$ Pharmacist in Research and development, PHY Physician, PM Policy maker, PTECH Pharmacy technician, PT_IPD Patient in In-Patient Department, PT_OPD Patient in Out-Patient Department, PUB Public/general population, ST Student, PR Parent, U1 University1, U2 University2, U3 University3, U4 University4, U5 University5 


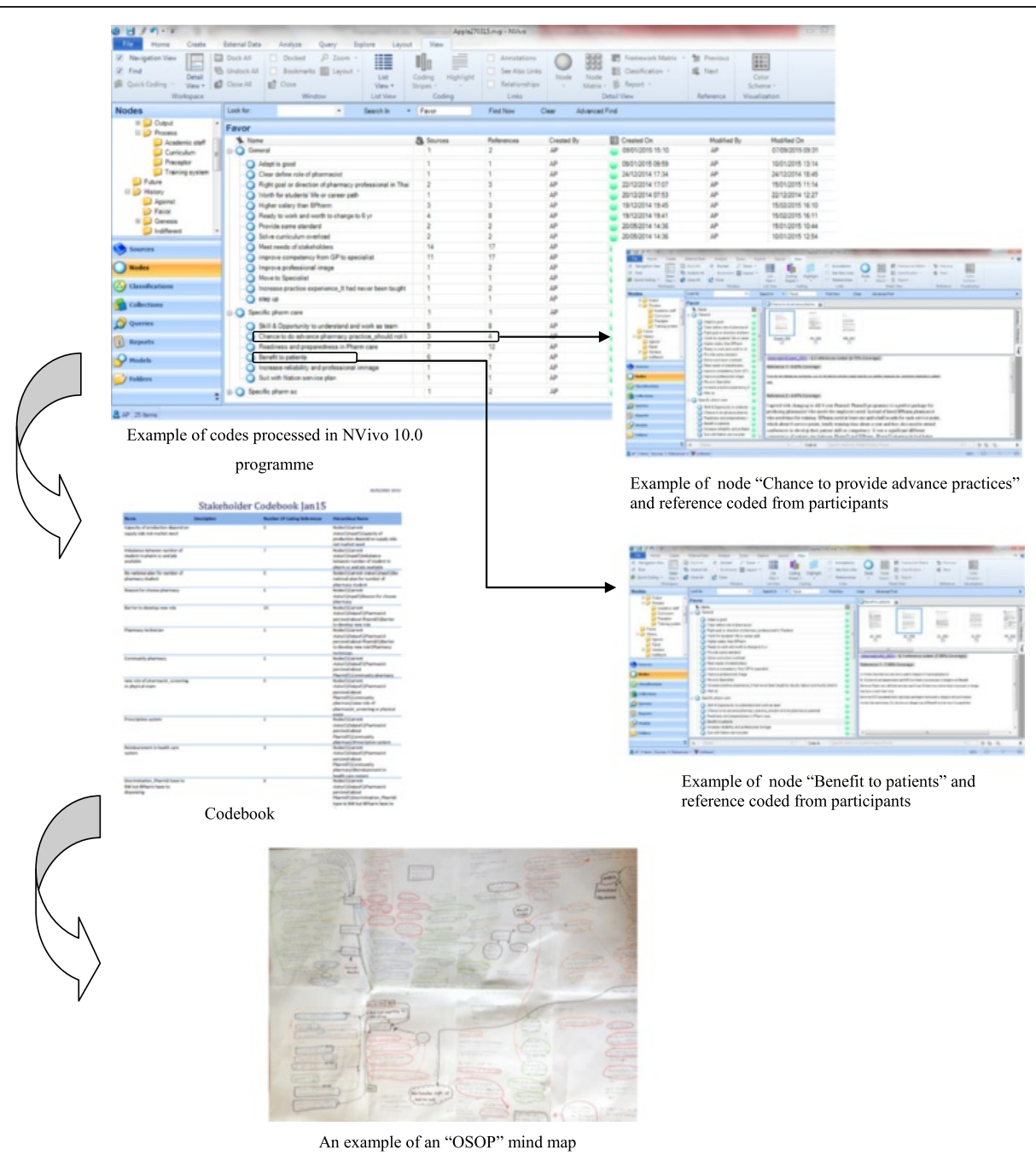

Fig. 2 The process of theme development with the "One Sheet of Paper, OSOP" method

Theme 1: Influences of an all-PharmD policy 4

The most frequent influence of an all- PharmD policy noted in the findings was the need for pharmacists to provide a better standard of patient care due to the competencies of pharmacy graduates from the previous pharmacy programme (a 5-year BPharm) being too broad and not being suitable for pharmacy practice in the patient care area in Thailand. The detailed themes and subthemes are presented in Fig. 3. The subthemes and supporting quotes are presented in Table 4.

"Hospital pharmacists should have the in-depth knowledge to serve patients by doing more than dispensing medication, so a PharmD in pharmaceutical care is the answer." (Policy maker 9)

Policy makers who were involved in this transition remembered the initiatives of this change as part of a global trend towards providing patient care services.
"We considered the direction at an international level and saw that the trend for developed countries was normally to adapt a practice role that emphasised patient care. This might be more suitable due to the PharmD programme giving us higher competencies as pharmacists." (Policy maker 1)

A factor that has also been mentioned as an influence on the transition to an all-PharmD programme was the Cooperation of four faculties of pharmacy and the Bureau of Health Service System Development, Ministry of Public Health (MoPH), in the development and establishment of a master's degree in clinical pharmacy programme via a modular system. This foundation of clinical pharmacy activities in real workplace settings was supported by the US-Thai consortium for the development of pharmacy education in Thailand (founded in May 1994 by the Pharmacy Education Consortium of Thailand, PECT). 


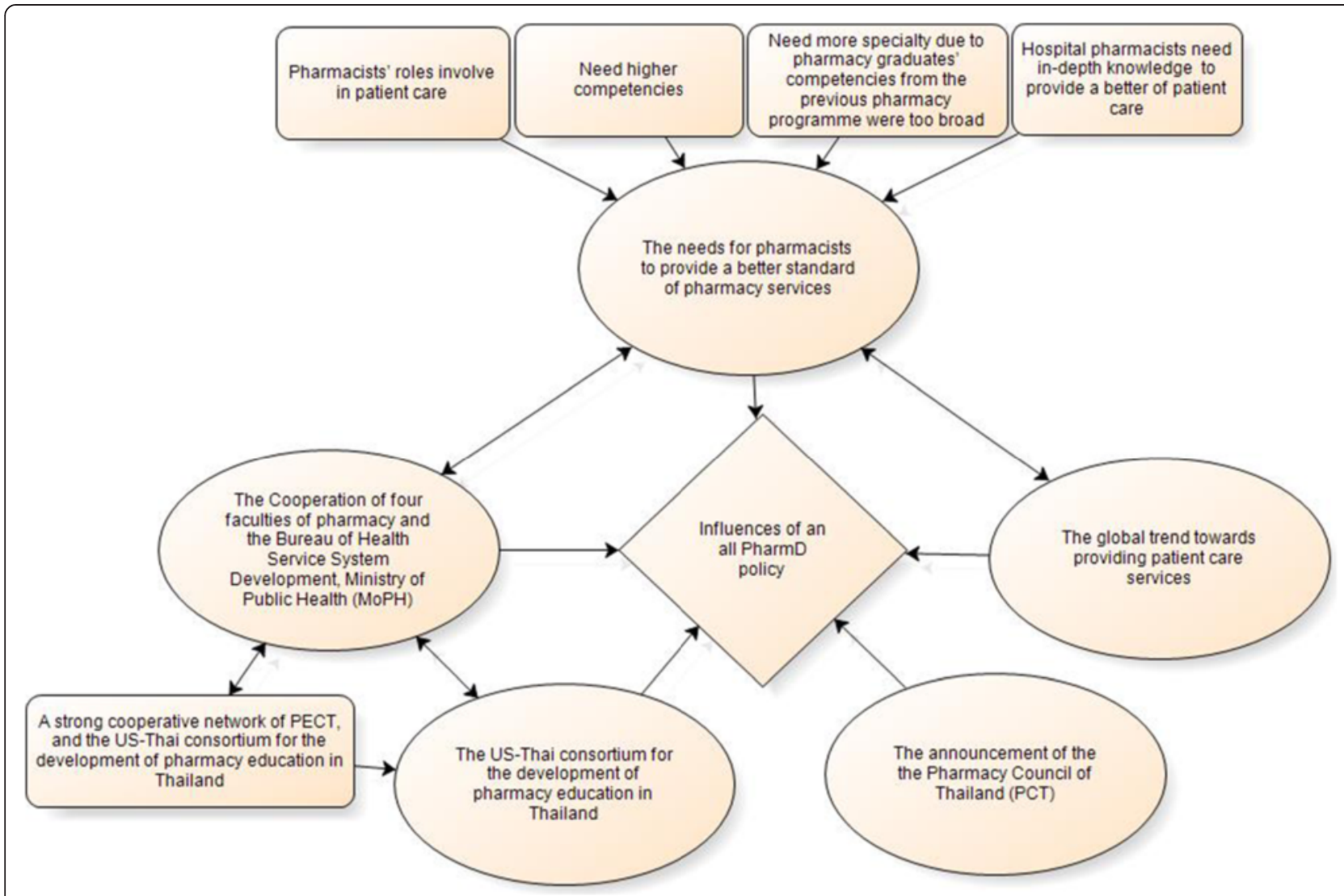

Fig. 3 Theme "Influences of an all-PharmD policy"

"The result of the consortium has had a great impact on Thai pharmacy education and the Thai pharmacy profession." (Policy maker 10)

The mission of this consortium was to provide Thai pharmacy academic staff and pharmacists, who were selected by a Royal Thai Government Panel, to access advanced professional (PharmD) or graduate $(\mathrm{PhD})$ studies and training in selected pharmacy schools in the US. Pharmacy educators adopted the US PharmD programme to establish the first Thai PharmD programme (pharmaceutical care) at the Faculty of Pharmaceutical Sciences, Naresuan University in 1999.

However, the big drive came from the announcement of the Pharmacy Council of Thailand (PCT) in 2008 that, starting in 2014, all new pharmacy graduates would have to graduate from pharmacy faculties accredited by the Council through the 6-year PharmD curriculum only.

"The Pharmacy Council stated that if we did not provide a 6-year PharmD curriculum, our students will not qualify to take the licensure examination. All faculties have to adapt their curriculum for all their programmes to 6 years." (Academic member 21)

\section{Theme 2: Perceived benefits of the transition of pharmacy} education to an all-PharmD programme

Most interviewees from academic institutions and pharmacy practitioners perceived benefits of the transition to an all-PharmD programme because it was a step-up process for pharmacy education and the profession and because it enhanced a move from generalists to specialists, while graduates' users (e.g., patients, health care teams and employers) perceived benefits as the PharmD graduates would have a higher competency to meet their needs. The detailed themes and subthemes are presented in Fig. 4. The subthemes and supporting quotes are presented in Table 5.

\section{Step-up process}

Thai pharmacy education has changed from the 5-year BPharm degree (with three main tracks: PC, PSc, SAP) and the 6-year PharmD degree focused on patient care to a single national PharmD programme (offering both pharmaceutical care (PC-PD) and industrial pharmacy (IP-PD). Faculty members thought that this change was a step up for the pharmacy profession and for pharmacy education in Thailand. 
Table 5 Subthemes and supporting quotes within the theme "Perceived benefits"

\section{Key theme: Perceived benefits}

\begin{tabular}{|c|c|c|c|}
\hline Subthemes & Concepts & Participants $^{a}$ & Example of supporting quotes \\
\hline \multirow{6}{*}{$\begin{array}{l}\text { Step- up } \\
\text { process }\end{array}$} & \multirow{2}{*}{$\begin{array}{l}\text { Change from BPharm to PharmD } \\
\text { degree }\end{array}$} & AC4_PC_U3, AC19_PC_U3 & \multirow{2}{*}{$\begin{array}{l}\text { "It was a step up from the Bachelor degree to the professional } \\
\text { degree which is a 6-year professional degree similar to other health } \\
\text { professions such as physicians and dentistry."(AC 4_PC_U3) }\end{array}$} \\
\hline & & AC20_PC_U3 & \\
\hline & \multirow[t]{2}{*}{$\begin{array}{l}\text { Increase reliability and improve } \\
\text { professional image }\end{array}$} & AC_D_U3, & $\begin{array}{l}\text { "This change might increase reliability to pharmacy } \\
\text { professional."(PH2_HOS) }\end{array}$ \\
\hline & & PH2_HOS, PH23_PB, PH21_IP, PH21_IP, PH13_MP, PH14_RD, PM1 & $\begin{array}{l}\text { "We should give the good services first so we will get trust from } \\
\text { public." (PM1) }\end{array}$ \\
\hline & \multirow[t]{2}{*}{ Higher salary than BPharm } & \multirow[t]{2}{*}{ EXP9_HOS, EXP10_HOS, PH24_HOS, PH14_COM, PH18_COM, PR2, ST9 } & $\begin{array}{l}\text { "The career progression of PharmD pharmacist is faster than a } 5 \text { year } \\
\text { programme. The } 6 \text {-year PharmD graduates have higher salany than a } \\
5 \text { year pharmacist who works for } 3-4 \text { year before PharmD graduates." } \\
\text { (EXP10_HOS) }\end{array}$ \\
\hline & & & $\begin{array}{l}\text { "Career ladder is also good because a } 6 \text { year graduates had salary } \\
\text { which equivalence to a Master degree. Duration to higher position }\end{array}$ \\
\hline
\end{tabular}

Move from generalists to specialists

Chance to provide an advance pharmacy practice

Increase skills and understanding for working with teams

Clear definition of pharmacists' roles

AC9_SAP_U1, N1, PH2_HOS, PH25_HOS, PHY5

Improve competency from general to specialist

AC3 PC U4, AC21_D U5, AC22 D U1, EXP2 COM, EXP9_HOS, EXP10_HOS, EXP11_MP EXP13_HOS, PH24_HOS, PHY1, PHY4, PM1, PM2, PR1, ST1, ST6, ST7

Right direction of pharmacy profession

No more duck

Open new markets in pharmaceutical

AC17_SAP_U1,PH29_COM, PH30_COM, PM5, PM8 sciences
EXP13_HOS, PM1, PH2_HOS, ST8

PH19_RD, PH22_HOS, PM1, ST3, ST4, ST5

\section{AC22_D_U2, AC25_U3, EXP9_HOS, PH2O_IP, PH25_HOS, PM1}

EXP9_HOS, PH23_PB, PH24_HOS, EXP13_HOS, AC13_PC_U1

"A 5-year BPharm programme does not make us experts either in medicines or patient care. This 6-year programme would give us higher competencies." (PM 1)

"PharmD graduates had better skills in patient care. They had more confident and work well with health care team." (PH2_HOS)

"The intention of PCT was good. They proposed to clarify the position of the pharmacy profession which might useful to our society and our profession." (EXP13_HOS)

"We see the clearer picture of patient care. It is a view, that this is the direction we are going to do and the old curriculum was still missing a lot of thing that we need to learn." (PM1)

"Pharmacy professional will be looked clearer from this pharmaceutical care." (PH2_HOS)

"Pharmacist should prepare for specialty as well so they can work as a health care team and easy to communicate." (PHY4)

"It is the right way and it was partial success. I give credit to everyone. Everyone has good intention but it will be sustained or not." (AC13_PC_U1)

"A 5-year BPharm programme does not make us experts either in medicinal products or patient care. This 6-year programme would give us higher competencies." (PM1)

"We are too broad, like a duck. We should good at something better than know everything, but we are not good in anything." (ST3)

"Job markets are still available but we have to open new markets, such as areas in vaccines, blood substitutes, nanotechnology, in herbal medicine. Faculty should move to design our graduates." (PM5) 
Table 5 Subthemes and supporting quotes within the theme "Perceived benefits" (Continued)

Meet the need Patients and population: better care for AC3_PC_U4, AC5_SAP_U1, N1, N2 PHY5, PHY7, PH2_HOS, PH15_COM, "PharmD graduates have better skills in patient care They are more

of stakeholders patient PH16_COM, PH14_MP, PM9, PT_IPD4, PT_OPD2, PT_OPD6, PT_TECH1,

PT TECH2, PUB2, PUB5

Patients and population: need pharmacist to talk about their medicines

Patients and population: pharmacists are able to create the better world

Patients and population \& Health care teams: PharmD graduates provided good services
Meet the need Employers: ready to work of stakeholders (continued)

\section{PT_IPD2, PT_IPD4, PT_TECH4, PT_TECH5}

EXP2 COM, N3, N5, N6, PHY2, PHY6, PT IPD1, PT IPD3, PT_IPD4, PT IPD5, PT OPD1, PT OPD2, PT OPD3, PT OPD4, PT OPD5, PT_OPD6,

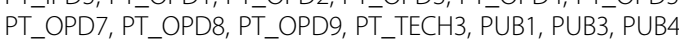

confident and work well with health care teams." (PH2_HOS)

"Employers from hospitals and community pharmacies had high satisfaction with PharmD graduates." (PM9)

"For the 6-year Pharmacy programme

I think it must be good. I know that if patients have problems with medicine they can talk with a pharmacist and the pharmacist will talk to the doctor for them. It makes for better care for us." (PT_OPD2)

"Pharmacist told us about how many tablets

we have to take or what the medicines used for. But I think it is not enough. They should tell us more about how to monitor other symptom s which might happen or how to monitor about side effect." (PT_IPD4)

"I am glad to know that some faculties encouraged their pharmacy students to visit homes in poor community and help people about drug related problems. Students should know about suffering in people's life who did not know their right to accessible to health care system.

Pharmacy professional had impact on society and pharmacists are able to create the better world." (PUB7)

"The 6-year pharmacists help us to adjusted doses, increase patients" compliance and follow-up drugs 'side effects." (PHY2)

"I think it is good to have a pharmacist on ward. We discuss and shared opinions which is beneficial for our patients." (PHY6)

"They (PharmD graduates) explained very well. They told me about diet, exercise and medicines." (PT_OPD1)

"Her (PharmD graduates) service is very good. She takes a good care to patients. I feel courage and able to talk with her. She makes us feel warm. She is willing to treat us. I feel confident in her knowledge for 100 percent sure." (PT_OPD2)

"Pharmacist taught me how to use this medicine. I have to remove it from the sealed pouch, peel off this, and clean the skin that the patch will be applied. Pharmacist also told me that this medicine will have side effect."(PT_OPD5)

"The 6 year graduates are very important team member especially in medicinal wards and ICU." (N3)

AC6_SAP_U4, EXP3_HOS, EXP9_HOS, EXP10_HOS, EXP8_PB, PH2_HOS, PH10_HOS, PH24_HOS, PH25_HOS, PH16_COM are ready to work. It fulfil the need of employers" (AC6)

"The 6-year PharmD programme is a perfect package. There was a significant different in the competency of patient care between PharmD and BPharm. I will choose a six year programme graduate because they are ready to use." (EXP9_HOS)

"PharmD graduates have the skills to approach other health care providers. They are ready to work after graduation." (EXP10_HOS) 
Table 5 Subthemes and supporting quotes within the theme "Perceived benefits" (Continued)

Policy makers and educators: solve $\quad$ AC2_PC_U4, PH2_HOS, PM5

curriculum overload

Students and parents: worth for student' life and career

PH25_HOS, PR1, PR3, PR4, ST2

Patients and population: increases study period will produce pharmacist

who provide better care for patient

Policy makers and educators: improve readiness and preparedness in Pharm care tract

Meet the need Health care teams: Increase skills and of stakeholders (continued) health care team
PHY5, PH26_HOS, PM8, PTECH3, PT_IPD4, PT_IPD5, PT_OPD6, PUB6

AC1 PSC U1, AC2_PC_U4, EXP9_HOS, EXP13_HOS, PH9_HOS, $\mathrm{PH} 25$

AC4 PC U4, AC18 PC U3, AC19_PC U3, EXP11_MR, N1, PH10_HOS, PH25 HOS, PHY5, PTECH1, EXP11 MP
"I think the 6-year PharmD programme is good because I graduated from a 5-year programme which was too tight and clerkship period is too short." (PH2 HOS)

"The previous programme had curriculum overload but still lack of skill. Policy makers discussed about this issue that if we change to a 6 year curriculum, this will provide more time to practice." (PM5)

"I think it is worth another year. It is an opportunity to choose the way of life from the internship experience. Learning a six year programme made the longer internship and had much more experiences." (PH25 HOS)

"The 6-year programme provides more practice and includes additional things to learn." (PRT)

"I think the-6 year programme is worth. We can expose the real situation. In the sixth year we had clerkship all year. It is very useful that we can learn a lot from training." (ST 2)

The time for practicing in previous programme was too short and had too much type of training sites." (PM8)

\section{Contrast view}

"I think all pharmacists have high competence. There was no different between a 5-year and 6-year graduates. They did not have a different job description. They are working together." (PTECH3)

"It will be very useful toward preparing the student for their work. A 5 -year programme provided only 3 months of training rotation. They have not enough time to practice." (EXP 13_HOS)

"PharmD graduates had better skills in patient care. They had more confident and work well with health care team." (PH9 HOS)

"The 6-year pharmacy graduates have higher knowledge. Their views or critical thinking seem wider or have more understanding about the concept of a multidisciplinary team. We are friends who will walk together." (N1)

"We extend to six year in order to do more work with patient. We had the opportunity to work with doctors and nurses. When we work with team, I felt that I am valuable. Dispensing is limiting our potential. We used fully potential when we work on ward."(PH25_HOS)

"We work as health care team. Doctors cannot work by themselves. The processes need other profession to take care and check.

Pharmacists help physicians about medicines. That is a confirmation process for the best care to our patients." (PHY5)

"The six-year graduates have more in-depth knowledge." (PTECH1)

"At that time our country had both 5-year programme and 6-year programme that might have some confusion in term of the difference of certified of degree and salary of graduates." (AC22_D_U1)
Policy makers and educators: provide the same standard of curriculum
AC22_D U1, EXP13, PM3, PM8 
Table 5 Subthemes and supporting quotes within the theme "Perceived benefits" (Continued)

"They all have to be graduates of the six-year programme and

Health care teams: increase skills in home health care and holistic care

EXP12_COM, PH4_HOS, PH5_HOS, PH25_HOS, PH26_HOS, PH27_HOS,

Health care teams: need specialised pharmacist for teams

Policy makers and educators: suit with AC3_PC_U4, EXP9_HOS, PH7_HOS, PH8_HOS, PH12_HOS National service plan
EXP3_HOS, EXP8_PB, PH11_HOS, PH28_HOS, PHY4, N4, N6

\section{managed in a sin \\ naged in a similar manner." (PM 3)}

The six-year graduates provide home health care service and follow up patient at home. They work like a family medicine but they are family pharmacist. They had been added this skill. In the past, they manage only medicine, but now they provide holistic care to patients. (PHY3)

"Pharmacist should prepare for specialty as well so they can work as a health care team and easy to communicate." (PHY4)

The 6-year programme follows context of national policy towards health care and services excellence in Asia pacific. The National

service plan also encourage the developing of pharmacy services in all level of care." (AC3_PC U4)

\section{${ }^{\mathrm{a} A b b r e v i a t i o n}$}

$A C \_P S C$ Academic member in pharmaceutical sciences area, $A C \_P C$ Academic member in pharmaceutical care area, $A C \_S A P$ Academic member in social and administrative pharmacy), $A C \_D$ Dean, EXP_HOS Expert in hospital pharmacy, EXP_COM community pharmacy, EXP_PSC Expert in industrial pharmacy, EXP_PB Expert in public health and consumer protection, EXP MP Expert in marketing pharmacy, N Nurse, PH_HOS Hospita pharmacist, $P H$ COM community pharmacist, $P H I P$ Industrial pharmacist, $P H P B$ Pharmacist in public health and consumer protection, $P H M P$ Pharmacist in marketing pharmacy, $P H \quad R D$ Pharmacist in Research and development PHY Physician, PM Policy maker, PTECH Pharmacy technician, PT IPD Patient in In-Patient Department, PT OPD Patient in Out-Patient Department, PUB Public/general population, ST Student, PR Parent, U1 University1, U2 University2, U3 University3, U4 University4, U5 University5 


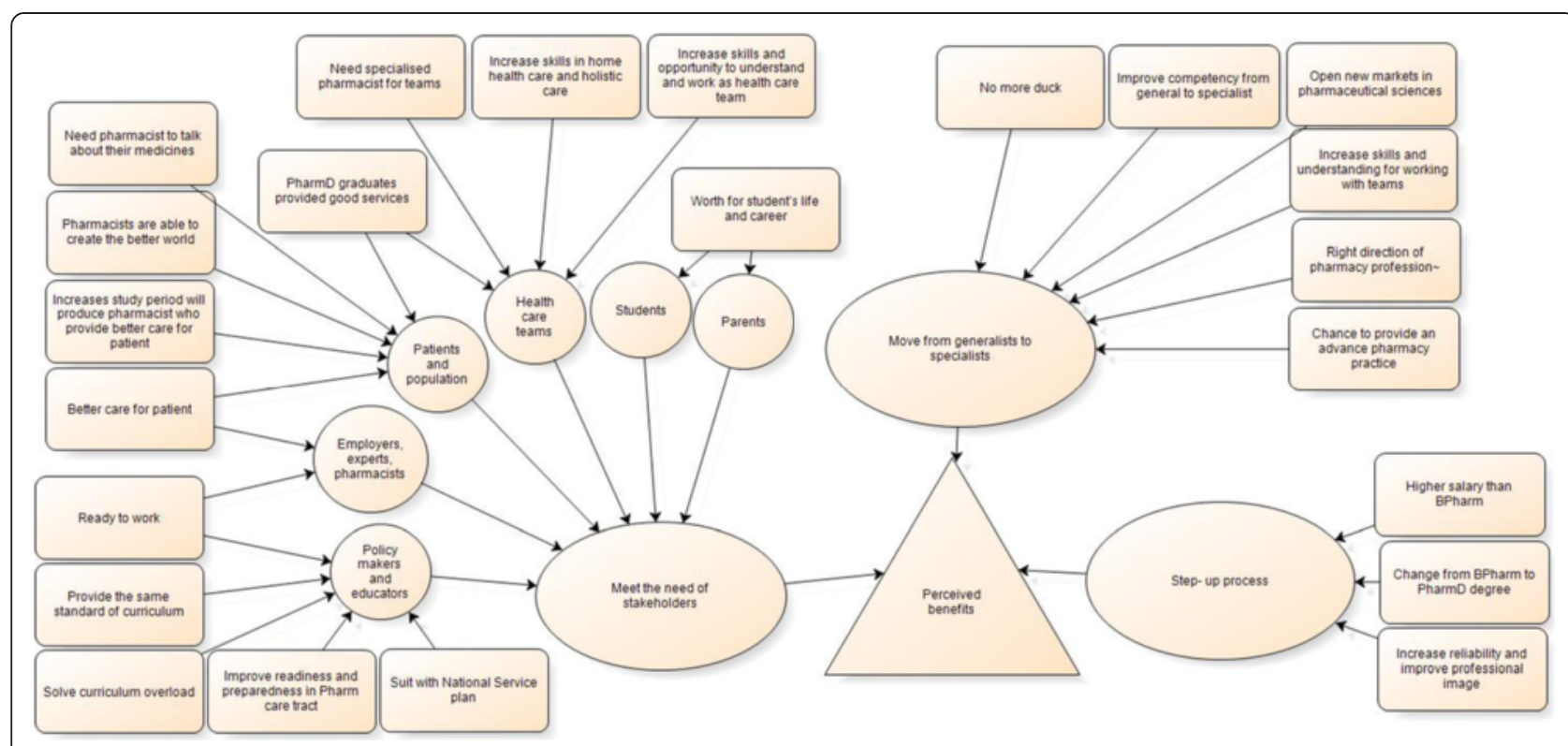

Fig. 4 Theme "Perceived benefits"

"It was a step up from the Bachelor degree to the professional degree, which is a 6-year professional degree similar to other health professions such as physicians and dentistry." (Academic member 4)

Unfortunately the Thai government originally gave the PharmD the same status as a bachelor degree due to it being an entry level programme, but they later rewarded progression by matching the promotions and salaries of PharmD graduates similar to those with a master's degree. Other 6-year programmes that have also been awarded similar to a master's degree include the Doctor of Medicine (MD), Doctor of Dental Surgery (DDS) and Doctor of Veterinary Medicine (DVM) in Thailand.

\section{Move from generalists to specialists}

The direction of pharmacy education in Thailand was not clear before the transition process. After the pharmacy council announced the all-PharmD policy, there were efforts to equip existing pharmacists with specialised competencies. Most interviewees thought that the transition to the 6-year programme would improve pharmacy competencies from generalists to advance general pharmacists or specialists. The frequent phrase noted in the findings was "the Thai pharmacist should not be a duck anymore". The Thai meaning of duck is that this bird is able to perform many tasks (e.g., flying, running and swimming) but does not excel in any of them.

"We are too broad, like a duck. We should be good at something better than knowing everything, but we are not good in anything." (PharmD Student 3)
"A 5-year BPharm programme does not make us experts either in medicinal products or patient care. This 6-year programme would give us higher competencies." (Policy maker 1)

However, some experts and academic members perceived that the specialisation in the 6-year PharmD graduates might suit only in patient care area rather than other areas (e.g., industrial pharmacy, pharmacy marketing).

\section{Meet the needs of the stakeholders}

The minimum credit requirement for the 5-year BPharm programme was 150, whereas the 6-year PharmD programme requires a minimum of 220 credits. The 6-year PharmD programme requires 2,000 h of practice training, which is $1,500 \mathrm{~h}$ more compared to the 5 -year BPharm programme. The increased credits in the 6-year PharmD curriculum provide in-depth knowledge within special tracks. The one-year extension provides the PharmD students with more practice rotations. The stakeholders expect the PharmD graduates to have higher competencies and be ready to work as pharmacists due to the greater number of didactic credits and the longer training experience.

"The 6-year programme provides more practice and includes additional things to learn." (Parent 1)

The majority of pharmacists who work in pharmaceutical care areas perceived the benefits of the PharmD programme, such as preparing PharmD graduates for work immediately after graduation, understanding other health care professionals, and providing high quality patient care. 
Table 6 Subthemes and supporting quotes within the theme "Concerns" Key theme: Concerns

\begin{tabular}{lll}
\hline Subthemes & Concepts & Participants $^{\mathrm{a}}$ \\
\hline Higher cost of study and value & $\begin{array}{l}\text { Cost of education to parents and the } \\
\text { government budget }\end{array}$ & AC12_SAP_U4, EXP4_PSC, PR1, PR3, ST1
\end{tabular}

"The negative effect is the cost of education to parents and the government budget of at least six hundred million baht $(£ 12,253,000$ or $\$ 18,421,000)$ a year, without being able to see the benefit in the short or long term. Improving pharmacists' competencies is a great thing but we have many ways to improve them, such as, via studying or working in real life situations." (AC12_SAP_U4)

"A 5 yr programme will not increase cost. This increasing cost gave a burden to the government, students and users or employers due to when we had longer period of study, we will ask higher rate of salary in both public and private sector." (EXP4_PSC)

"I think the cost is quite heavy. In case where we do not have money, this might be a problem." (PR 1)

"The cost is not much harder because he (her son) helps himself. He got a scholarship from the faculty and works part-time job with his teacher. When he comes back home, he rarely asks for money. He needs only approximately 5,000 baht (£100 or \$150) per month. He is a very good saver. He rarely buys new clothes." (PR 3)

"The Pharmacy Council should prepare salary or compensation for our degree. I heard that they increased our salary by only 1,000 baht ( $£ 20$ or \$31) a month compared to the 5 year programme. It is not worth it to study another one year, when we have to spend approximately 100,000 baht ( $f 2042$ or $\$ 3070$ ) for this extended year. There should be other ways to encourage us to work hard and deserve our salary." (ST1)

"I think about the difference between a $6^{\text {th }}$ year pharmacy student who has clerkship with an unprepared preceptor for one year and a 5-year pharmacist who works for one year. They should have different levels of maturity." (AC12_SAP_U4)

"IP-PD student study for 6 year in laboratory and train for R\&D but they work in community pharmacy due to the higher salary. They did not use their knowledge and their specialty. It wasted their time and opportunity to work because they have to study and training for one more year instead of working."

(AC11_PSC_U5)

"Improving pharmacist's competency is a great thing but we have many ways to improve it, such as, via studying or working in real life situation. I did not see the benefit of the extended for one year or the worth of this change. Why it should not be Master degree instead of bachelor degree. Parents have to susport cost for another year and social lost pharmacist for support cost for another year and 
Table 6 Subthemes and supporting quotes within the theme "Concerns" (Continued)

A 5-year programme still need in some areas

EXP4_PSC, EXP10_HOS, PM10, PHY7

Thai context different from the US context

AC16_SAP_U2,PM2, PM9, PM10

Mismatch between the pharmacy graduates'

competencies and the

requirements of the job market
Mismatch competency and market' needs within pharmaceutical care trac e.g. hospital and community

pharmacy settings)

Mismatch competency and market' needs within industrial pharmacy trac
"They loss opportunity to work. If they graduate in five year, they will work faster for 1 year." (EXP4_PSC)

"A 5-year programme in Pharmaceutical had enough and appropriate basic knowledge to work as pharmacy

professional." (EXP4_PSC)

"I think they are suitable to work in hospital setting but detailer might not need 6 years or production line in hospital might need a 5 year programme." (EXP10_HOS)

"I want it to be a voluntary PharmD, rather than all six year PharmD. Who want to learn six year, they can learn. Five year curriculum is also need." (PM10)

"I think the 6 year programme probably too much due to their services might not need to study for 6 years. Most of them might not work with patient in the hospital. Some pharmacists work at community pharmacy that might need the different competencies." (PHY7)

"I do not see the benefit of the extended one year or the worth of this change. Why should it not be a master's degree instead of a bachelor degree? Parents have to support the cost for another year and society has lost a pharmacist for another year." (AC16_SAP_U2)

"We are not prosperous but we are not very poor either. We should undertake appropriate education. The issue is that we would like to follow the western model. We can find our own way. I do not think six years is the best study programme in the world." (PM10)

"In the past, the basic skill of Thai pharmacist is able to work as a community pharmacist. Now, the responsibility of community pharmacy had totally changed. Within PC-PD programme, it should be separated into hospital pharmacist and community pharmacist because they have different required competencies." (EXP 1_COM)

"Some faculties taught their PC-PD graduates that they should work in hospitals only. Students told me that they were not interested in community pharmacy but came here because it is only a compulsory rotation." (EXP2_COM)

"The private sector hired graduates from other other areas such as scientists who have a PhD degree. If you compare pharmacists who have a bachelor's degree and scientists who have a PhD. pharmaceutical companies need PhDs more than pharmacists because they have more experience in $R \& D^{\prime \prime}$ (AC10_PSC_U5) 
Table 6 Subthemes and supporting quotes within the theme "Concerns" (Continued)

"Most of the pharm sciences students worked in community plants but they were not well trained." (AC11_PSC_U5)

"PSC-PD graduates should not do practice in community pharmacies unless they have been passed the training and gained skills and competency to qualify to work as community gharmacist." (EXP]_COM)

Although IP-PD graduates can work in other services such as community pharmacy but they can work in certain levels. It will be difficult when they work in advanced services. Community pharmacy career is improved the services. It will provide the services to chronic and complex diseases patients. IP-PD graduates will struggle." (PM9)

Number of IP-PD was higher than job AC1 PSC U1, PC10 PSC U5, AC13 PC U4, AC21_D U5, market needed AC22 D U1, PM7, PM9

Capacity of production depends on supply side

AC1_PSC_U1, AC15_PSC_U2, AC21_D_U5, PH1_HOS, PM4, PM 6, PM9 pharmacy graduates' market.
"The number of IP-PD students was higher than job market need. I knew the job market. I feel empathy for students." (AC1_PSC_U1)

"There is limited job position in pharmaceutical industrial. They need only 200 pharmacists per year. However, it still has pharmacy shortage. I do not know the reason why graduates do not want to work in industrial." (PM7)

"The number of pharm sc graduates should be reduced." (PM9)

"This is problem in a level of policy. We might not base on principles of market demand." (AC1_PSC U1)

"We have a readiness and preparedness in industrial pharmacy more than clinical pharmacy so we have the number of $I P-P D$ more than PC-PD."(AC15 PSC U2)

"Basically, our basic structure is mainly in pharmaceutical sciences area. Number of pharmaceutical sciences academic staff higher than Pharm care staff. So, we have high number of student in IP-PD tract because we have to consider about education management." (AC21 D U5)

IP-PD graduates have a competitor in AC11_PSC_U5, EXP7_PB, PM7 the job market

Need more communication

"Pharmaceutical company need PhD more than pharmacist because they had more experience in R\&D." (AC11 PSC U5) (Note: PharmD degree in Thailand equivalent to Bachelor (Note: Phare)

"The opportunity of the 6-year IP-PD students would be less because manufacturers might hire a 4-year scientist instead. It might save cost for manufacturers. Pharmacist will have competitor in the job market." (EXP7_PB)

"I feel uncomfortable about this change. It needed more consideration before creating this new curriculum. It needed 
Table 6 Subthemes and supporting quotes within the theme "Concerns" (Continued)

AC1_PSC_U1, AC3_PC_U4, AC9_SAP_U1, AC12_SAP U4,

Plan to develop preceptors and teacher practitioners AC13 PC U1, AC21 D U5, AC22 D U1, EXP4 PSC, EXP5 PSC, PM1, PM4, PM5, PM10, ST1 AC13_PC_U1, AC18_PC_U3, AC19_PC_U3, AC20_PC_U3, AC22_D_U1, EXP3_HOS, EXP4_IP, EXP5_IP, EXP7_PB, EXP8 EXP9_HOS, EXP12_COM, PH3_HOS, PH9_HOS, PH6_HOS, PH7_HOS, PH10_HOS, PH11_HOS, PH12_HOS, PH15_COM, PH16 COM, PH2O IP, PH21_IP, PH24_HOS, PH25_HOS, PM3, PM4, PM9, PM10

communication to answer questions such as the necessity for change, the direction of change, and the main barrier that should be considered." (AC13 PC U1)

"There was confused about Pharmaceutical sciences. What is their scope and competency? Someone said all work which is non-pharm care is pharm sciences. We have to discuss about their competencies, regarding to the need of users." (EXP5_PSC) "It's a top down policy of the powerful people at that time. It should have more serious consideration of views or listening to each other." (PM10)

"Everything was move too fast. Even policy is suite for the future but we have no personnel to serve the policy. We should prepare PharmD preceptors then change to an entry level PharmD."(AC3_PC_U4)

"There was many problems such as preceptors were not ready, academic staff also were not ready." (EXP5_PSC)

Contrast view

"We have been informed about this change for many years before the PCT announced."(AC15_PSC_U2)

"It seems like question of "Which came first the chicken or the egg?" If preceptors are not ready, we should train them. If preceptor is not enough, we have to increase the number of preceptor." (PM2)

"We have to have our own staff to teach our students at practice sites because pharmacists have high workload. We have MOU with hospitals and have a great support from both faculty and hospital administrators." (AC5 SAP U1)

"It increases the load of preceptors, of which they are still the same number. Every faculty is competing." (AC22_D_U1)

"Increasing to the 6-year programme and release students out into the real world to find experience for themselves is not the right way. Lecturers or master's degree students should be trained and transfer their experience to students. At least 20 students will be trained at each site, but the site employs only one pharmacist." (PM4)

AC3_PC_U4, AC5_SAP_U1, AC18_PC_U3, AC19_PC U3, AC20_PC_U3, AC21_D_U5, AC22_D_U1, AC23 D U2, AC24_D U3, AC25 PC U3, EXP3 HOS, EXP4 IP, EXP5 IP, EXP7 PB, EXP8_PB, EXP13 HOS, PH9 HOS, PH19 RD, PM9

"Newly PhD or young staff are work hard for faculty but they did not have time to do their own career ladder. Leaders have to protect them. We should have a good mentor for them. (AC3_PC_U4)

"The most important factor in the new programme is preceptors and teacher practitioners. We have teacher practitioners (TP) to 
Table 6 Subthemes and supporting quotes within the theme "Concerns" (Continued)

Lack of resources (continued) Lack of academic staff in pharmaceutical care area

Lack of practical experience of the faculty members in both pharmaceutical care and pharmaceutical sciences

Separate licences separate license

AC2_PC_U4, AC8_PC_U4, PH2_HOS, PH6_HOS, PH10_HOS, PH11_HOS, PH24_HOS

AC10_PSC_U5, EXP6_PB, EXP13_HOS, PH25_HOS, PH16_COM, PH17_RD, ST8, PH021_IP, PH23_PB, PH30_COM

AC2 PC U4, AC4 PC U3, AC9 SAP U1, AC10 PSC U5, $A C 21-U 5, A C 25 P C \cup 3, P M 9$

work in hospital as teacher for students and also practice at training site." (AC5 SAP U1)

"Training pharmacy students is my responsibility. I am a pharmacist and I want to make the pharmacy profession stronger. I am proud to be a preceptor." (PH24 HOS)

"You want an effective preceptor but you never train us. Is it too demanding? We already have a high workload." (PH25_HOS)

"Some of them might not ready to train us because of they did not have enough time due to their high workload." (ST8)

"We need real expertise staff in pharm care that they should have residency degree or board certify but there were a very low number of this group of academic staff." (AC21_D_U5)

"Pharmacy graduates in pharm care preferred to work in the hospital more than to be a lecturer because of high salary and less stress. We are lack of lecturers and teacher practitioners." (PM9)

AC10_PSC 45, EXP1_COM, EXP2 COM, EXP5_IP, EXP13_HOS, "Most of academic staff works on their research but rarely work EXP7_PB in real practice settings." (EXP7_PB)

AC12 SAP U4, EXP1_COM, EXP2 COM, EXP5 PSC, EXP7 PB, PM1, PM5, PM6

"I encourage the separate license because each specialty required different competency. For example, within pharmaceutical care, there should separate into hospital pharmacist and community pharmacist. IP-PD should not practice in community pharmacies unless they pass the training and qualify to work as community pharmacist."(EXP1_COM)

"Pharmacy professional in each track will be developed. In far future, there is might be a separation of licensed." (PM1)

"The big issue was relating to license, but at that time, the council is not ready to give two licenses. As a result, every university have to change to six-year curriculum with one license." (PM5)

"Separate licences seems to narrow down pharmacists" opportunities to work in various settings. However, we need to be specialised, which requires different competencies. So, there should be separate licenses." (PM 6)

contrast view 
Table 6 Subthemes and supporting quotes within the theme "Concerns" (Continued)

"I did not agree about separate license. Why we have to close our opportunity? (EXP5_PSC)

Different programme and two examination

AC9_SAP_U1, AC10_PSC U5, AC11_PSC_U5, AC14_SAP_U5, PM6, PM9

Competencies of the entry level pharmacy graduates
EXP1_COM، EXP2 COM، EXP6_PB، EXP13_HOS, PM1, PM3, $\mathrm{PM} 10$
"If they study the difference programmes from first year, they should have difference license." (AC9_SAP_U1)

"We will have two pharmacy licensure examinations. The first examination is for the core competency. The second

examination is for the specialty. Why we have just only one license?" (PM6)

"The confusion in our pharmacy profession that we never talk is about the in- depth of core competency in the entry level PharmD programme." (EXPG_PB)

\section{${ }^{\mathrm{a}}$ Abbreviation}

AC_PSC Academic member in pharmaceutical sciences area, $A C \_P C$ Academic member in pharmaceutical care area, $A C \_S A P$ Academic member in social and administrative pharmacy), $A C \_D$ Dean, EXP_HOS Expert in

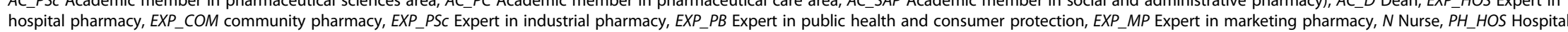
pharmacist, $P H \_C O M$ community pharmacist, $P H \_P$ Industrial pharmacist, $P H \_P B$ Pharmacist in public health and consumer protection, $P H \_M P$ Pharmacist in marketing pharmacy, $P H \_R D$ Pharmacist in Research and

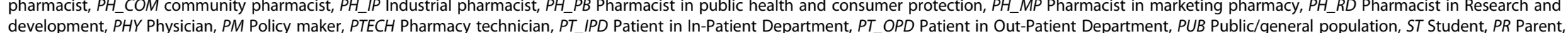
U1 University1, U2 University2, U3 University3, U4 University4, U5 University5 
"PharmD graduates have the skills to approach other health care providers. They are ready to work after graduation." (Pharmacy expert 10)

"PharmD graduates have better skills in patient care. They are more confident and work well with health care teams." (Pharmacist 2, hospital pharmacist)

Physicians and nurses also have positive perceptions towards the 6-year PharmD graduates' services and thought that they were effective members of the multidisciplinary team.

"I think it is good to have a pharmacist on ward. We discuss and share opinions, which are beneficial for our patients." (Physician 6)

"The 6-year pharmacy graduates have higher knowledge. Their views or their critical thinking seem wider or have more understanding about the concept of a multidisciplinary team." (Nurse 1)

Patients also perceived the benefits of pharmacists in the health care team, which would provide better care for them.

"For the 6-year Pharmacy programme, I think it must be good. I know that if patients have problems with medicine they can talk with a pharmacist and the pharmacist will talk to the doctor for them. It makes for better care for us." (Patient 2, Out-patient Department)
Most policy makers agreed that the transition to a single PharmD programme provided the same curriculum standard throughout the country.

"They all have to be graduates of the six-year programme and managed in a similar manner." (Policy maker 3)

\section{Theme 3: Concerns}

Interviewees such as hospital pharmacists, other health care providers and patients, students and parents, and academic staff in patient care areas were positive overall regarding the all-PharmD programme, while academic staff in the pharmaceutical sciences area and industrial pharmacy experts still had concerns about the curriculum change and suggestions for its improvement. The detailed themes and subthemes are presented in Fig. 5. The subthemes and supporting quotes are presented in Table 6.

\section{Higher cost of study and value}

Some academic staff thought that the policy makers should consider the increased cost of study due to the extra year. The students also discussed whether the increased cost of study was worth it.

"The negative effect is the cost of education to parents and the government budget of at least six hundred million baht $(£ 12,253,000$ or $\$ 18,421,000)$ a year, without being able to see the benefit in the short or long term. Improving pharmacists' competencies is a great thing but we have many ways to improve them,

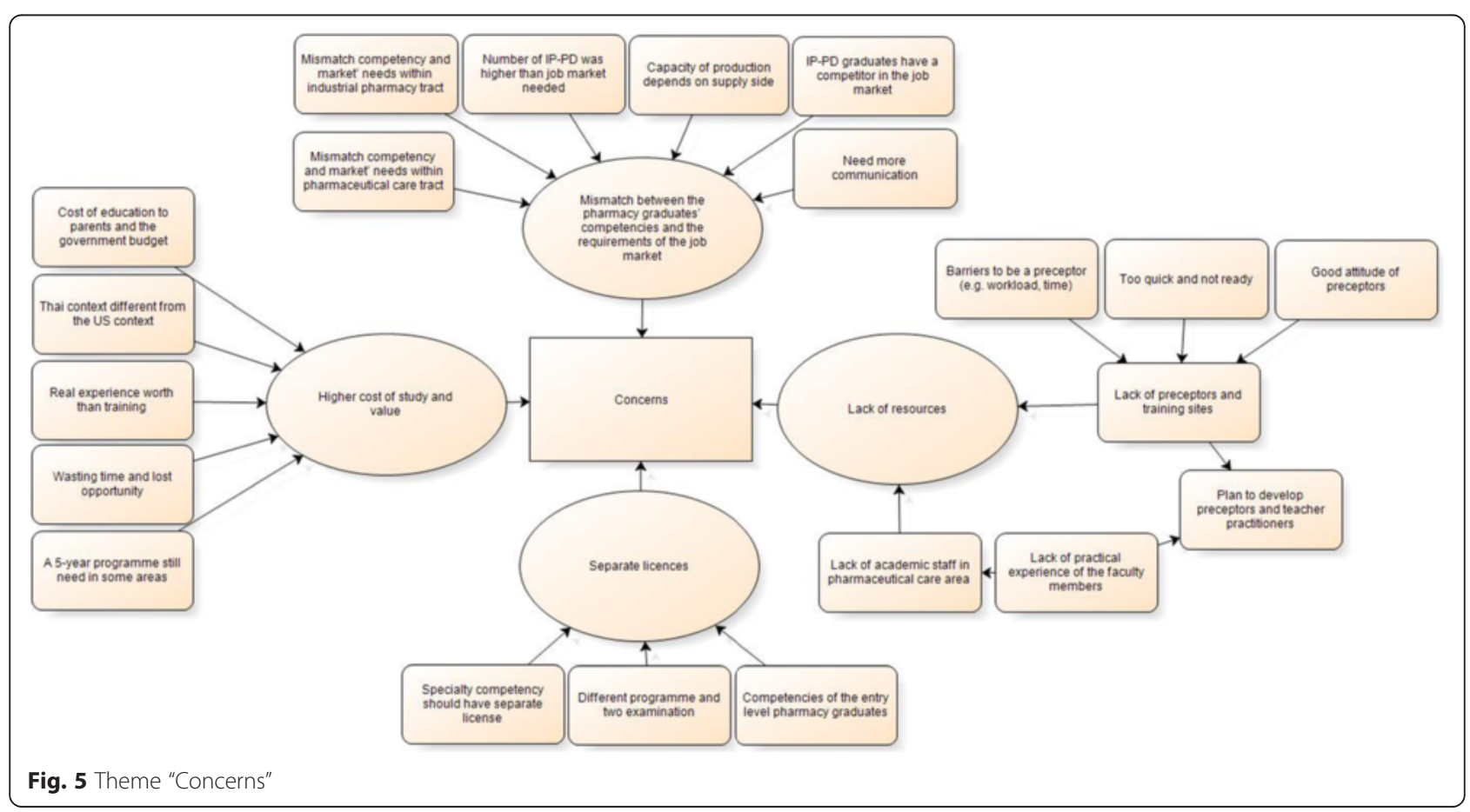


such as via studying or working in real life situations." (Academic member 12)

(Note: exchange rates on $08 / 03 / 2015 ; 1$ GBP $=48.967$ THB and $1 \mathrm{USD}=32.570 \mathrm{THB}$ )

\section{"The Pharmacy Council should prepare salary or compensation for our degree. I heard that they increased our salary by only 1,000 baht (£20 or \$31) a month compared to the 5-year programme. It is not worth it to study another one year more, when we have to spend approximately 100,000 baht (£2042 or \$3070) for this extended year. There should be other ways to encourage us to work hard and deserve our salary." (PharmD student 1)}

Some interviewees were concerned that this change might not deliver an effective pharmacy curriculum that is suitable for Thai context. They suggested that the new curriculum might cause problems in terms of students' time and money and might limit the ability to produce pharmacists who could quickly begin to work for Thai society.

"We are not prosperous but we are not very poor either. We should undertake appropriate education. The issue is that we would like to follow the western model. We can find our own way. I do not think six years is the best study programme in the world." (Policy maker 10)

"I do not see the benefit of the extended one year or the value of this change. Why should it not be a master's degree instead of a bachelor degree? Parents have to support the cost for another year and society has lost a pharmacist for another year." (Academic member 16)

Parents of pharmacy students who studied at private universities said that the cost of their children's education was at least 100,000 baht/year and approximately 500,000 baht $(£ 10,200$ or $\$ 15,300)$ in the $6^{\text {th }}$ year; the total cost was approximately $1,600,000$ baht $(£ 32,600$ or $\$ 49,100)$. One father thought that the cost might cause problems for some families who had low to medium incomes, but for him, it was acceptable.

"I think the cost is quite heavy. In cases where we do not have money, this might be a problem." (Parent 1)

Another interviewee, from a family with a low income, thought the cost of education at public university of approximately $40,000 \mathrm{baht} /$ year ( $£ 800$ or $\$ 1,200$ ), and that the total cost, which was approximately 300,000 baht $(£ 6,100$ or $\$ 9,200)$, was acceptable. Her son was granted a scholarship from his faculty and he was very careful with his money and also had a part time job for his living expenses. However, in terms of the cost of education, even at a public university, it is still a large amount of money for students' families.

"The cost is not much harder because he (her son)
helps himself. He got a scholarship from the faculty
and works part-time job with his teacher. When he
comes back home, he rarely asks for money. He needs
only approximately 5,000 baht ( 100 or $\$ 150)$ per
month. He is a very good saver. He rarely buys new
clothes." (Parent 3)

Mismatch between the pharmacy graduates' competencies and the requirements of the job market

The traditional PharmD programme focused on patient care but the PharmD curriculum in Thailand is divided into two main streams: a pharmaceutical care-PharmD (PC-PD) programme and a pharmaceutical Sciences or industrial pharmacy-PharmD (IP-PD) programme. However, both give students the same license to work across all sectors. There is a general consensus among the interviewees that the aim of the development of a 6-year programme in Thailand was to improve pharmacy competencies from generalists to specialists, focusing on pharmaceutical care and preparing pharmacy graduates to practice upon graduation in real workplace settings. Such preparations would serve to meet the required needs of the stakeholders. The greatest benefits of producing competent clinical pharmacists should be to patients, health consumers and Thai society.

However, community pharmacy employers presented contrasting views. Some argued that the pharmaceutical care aspect of the PC-PD is very hospital-centred and the skills acquired are more suited for tertiary and secondary care settings than primary hospital and community pharmacy settings.

\section{"Within the PC-PD programme, it should be separated into hospital pharmacist and community pharmacist because they have different required competencies." (Pharmacy expert 1, community pharmacy)}

"Some faculties taught their PC-PD graduates that they should work in hospitals only. Students told me that they were not interested in community pharmacy but came here because it is only a compulsory rotation." (Pharmacy expert 2, community pharmacy)

Pharmacists and pharmacy experts from the consumer protection area also shared the opinion that the curriculum should prepare pharmacy graduates for primary care services due to the higher number of primary care 
hospital settings (community hospitals and sub-district health-promoting hospitals).

On the other hand, the majority of the interviewees were less positive about the IP-PD graduates meeting the needs of the market; the number of graduates currently exceeds the needs of industry, and graduates from this track often have to pursue career paths in community pharmacy, a sector for which they are not prepared.

\section{"Most of the pharmaceutical sciences students worked in community pharmacies because they got higher salaries than industrial plants but they were not well trained." (Academic member 11)}

In addition, this view is also shared by participants from the industrial sector who believe that IP-PD graduates lack the research skills required for the research and development industry and often prefer to employ $\mathrm{PhD}$ holders of non-pharmacy science backgrounds.

\section{"The private sector hired graduates from other areas such as scientists who have a PhD degree. If you compare pharmacists who have a bachelor's degree and scientists who have a PhD, pharmaceutical companies need PhDs more than pharmacists because they have more experience in RED." (Academic member 10)}

In contrast, some policy makers perceived that the PharmD graduates will be more skilled in research and development, which might meet the needs of employers. There are plenty of opportunities to create the curriculum and make a difference for graduates, but this depends on the cooperation of the leader, dean and academic staff in the pharmaceutical sciences area to prepare this new curriculum.

\section{"Job markets are still available but we have to open new markets, such as areas in vaccines, blood substitutes, nanotechnology, in herbal medicine. Faculty should move to design our graduates." (Policy maker 5)}

To fulfil the needs of the IP-PD graduates' competency for the area of research and development, an integrated PharmD-PhD programme was developed at one of the universities in Thailand, aiming to prepare highly competent graduates to study in $\mathrm{PhD}$ programmes. This is an interesting programme designed to suit the needs of the pharmacy or pharmaceutical industry.

\section{Lack of preceptor and training sites}

The crucial issue for the transition to an all-PharmD programme is providing a sufficient number of qualified
PharmD preceptors. The new PharmD curriculum has a four-fold increase in the number of hours for practice training compared with the BPharm programme. However, the number of qualified preceptors remains the same. The PECT tried to establish a preceptor development programme to prepare for this change but the majority of the stakeholders perceived that this was still not enough.

"It increases the load of preceptors, of which there are still the same number. Every faculty is competing."

(Academic member 22)

Stakeholders felt there were benefits for institutions if they are offered as training sites (e.g., contributing to the pharmacy profession, updating preceptors' knowledge and skills, having highly competent academic members who are able to empower preceptors and enhance training sites and opportunities to recruit well-performing pharmacy students).

"Training pharmacy students is my responsibility. I am a pharmacist and I want to make the pharmacy profession stronger. I am proud to be a preceptor." (Pharmacist 24)

However, the majority of the interviewees had common concerns regarding the insufficient quantity and quality of preceptors. Stakeholders' perceived barriers towards formal preceptor preparation, such as the workload (e.g., high routine workload of the preceptors, lack of time/ money/management staff/space), inadequate role models, the need for more recognition and support from administrators regarding preceptors' roles, training sites requiring standardisation and quality assurance, career progression as preceptors and a reward system for their clerkship workload, the need to put in place a preceptor development programme and the establishment of an active memorandum of understanding (MoU)/long term commitment between training sites and universities.

\section{"You want an effective preceptor but you never train us. Is it too demanding? We already have a high workload." (Pharmacist 25)}

One employer in industrial pharmacy thought that the training patterns in the pharmaceutical sciences area should be reconsidered and needed changing. Academics who have more training in research should teach students about pharmaceutical sciences in the universities. This strategy might be better than sending students to be trained in industry, which has a limited number of preceptors, insufficient space and too few training sites. Of more concern, some trainers who were non-pharmacists in industrial 
pharmacy settings were diploma graduates who wondered about their qualification to teach pharmacy students.

"Increasing to six years and releasing students out into the real world to find experience for themselves is not the right way. Lecturers or master's degree students should be trained, and their experience will transfer to students. At least 20 students will be trained at each site, but the site employs only one pharmacist." (Policy maker 4)

\section{Lack of practical experience of the faculty members}

Deans and policy makers had planned to increase the number of instructors in the pharmaceutical care area due the lack of pharmacy practice staff within academic institutions. Unfortunately, they found it was difficult to recruit pharmacy graduates to work as instructors in pharmaceutical care within academic institutions because they preferred to work in other pharmacy practice areas such as hospital or community pharmacy settings due to higher salaries and less stressful environments.

"Pharmacy graduates in pharm care preferred to work in the hospital more than to be a lecturer because of higher salary and less stress." (Policy maker 9)

Highly performing academic staff in the pharmaceutical care area who have graduated from a pharmacotherapy residency programme are scarce and are in great demand. They also act as role models for PharmD students. Senior academics and experts said that they work very hard and that faculty have to take care of them and not let them become burnt out by the high workload.

\section{Separate licences}

Previously there has only been one type of license for Thai pharmacists across all pharmacy practice settings. Pharmacy graduates from both the BPharm and PharmD programmes have been required to take the same national licensure examination. However, the PharmD students who start their pharmacy education in and after 2015 will have to take two pharmacy licensure examinations: the first examination is for pharmacy core competency at the end of their fourth year and the second examination is for their specialised competency at the end of their sixth year. The examination had to be separated into two different examinations because those two tracks were very different in terms of their specialties (e.g., knowledge content, clerkship experiences and specialised skills) but they still have the same license. Separate licenses were mentioned in earlier stages of decision making.
Some faculty members were concerned about the vision of the Thai pharmacy profession. If it aimed to move practitioners from being generalists to specialist pharmacists, different types of pharmacy licenses should be offered. Some policy makers advised to offer separate pharmacy licences in the future, and pharmacists should not work across the professional pharmacy tracks; for instance, pharmacy graduates in pharmaceutical industrial should not work in community pharmacy because they may not have sufficient competency. Pharmacy professionals in specific areas should work only in their area because this represents a commitment to the development of the pharmacy profession in those specific areas. They might cross over to other tracks, but there should be a system to assess their competencies (e.g., taking a training course or continuation of their pharmacy education) to ensure the delivery of good pharmacy practice and to meet the required standard in each practice area.

'Separate licences seems to narrow down pharmacists' opportunities to work in various settings. However, we need to be specialised, which requires different competencies. So, there should be separate licenses." (Policy maker 6)

On the other hand, some academics said that there should be only one license. They thought that the advantages were as follows: an opportunity to work in various areas of pharmacy practice, as in the past, and one license would, or at least could, unite the pharmacy profession. The situation was frequently compared to the doctor's license: a doctor has only one license but different doctors might have different specialties.

\section{Discussion}

In the past three decades, the roles of pharmacists globally have changed dramatically. Pharmacists responsibility are not merely in compounding or dispensing medicines but in providing a professional role in patient care [7]. The main limitation to developing advanced clinical roles is a lack of clinical skills. The genesis of the 6-year PharmD programme in Thailand began from the needs of pharmacists who would like to develop themselves to provide a better standard of patient care. It was similar to the adoption of the PharmD in the US, Canada and South Korea that was led by the needs of clinical pharmacists who had higher competency in patient care $[10,89,90]$. The PharmD programme is the model for the pharmaceutical care programmes employed by many other countries [11]. It has been mentioned in many countries who have adopted, or plan to [8] adopt, this programme to produce pharmacy graduates who have high levels of knowledge and skill in pharmaceutical care and who work well together with other health care providers [7, 91, 92]. 
The strong cooperative network of PECT and the USThai consortium for the development of pharmacy education in Thailand appeared to be the most important influence on the development of the PharmD programme in Thailand [18, 20-22]. Another important influence is the regulatory body that has the authority to make the policy a reality. The process of the 'all-PharmD' programme has also been mandated by the authorities in many countries (e.g., Canada, Japan, South Korea) [7, 10, 93].

Interviewees in the pharmaceutical care area appeared to welcome the 6-year PharmD programme due to this new programme being a step-up process for the pharmacy profession that has the same curriculum duration as the MD or DDS degree, filling the gap left by the 5-year BPharm programme, which involved less practice and might produce a graduate who had insufficient competencies to practice on the job market today. This benefit was also mentioned in the adoption of a 6-year pharmacy programme in the US and South Korea [8, 94]. Another important benefit is that PharmD graduates are ready to work, with little support, following graduation and thus are becoming increasingly common and valued in the Thai health system $[21,95,96]$.

Thailand is among the world's middle income countries. An average monthly income per household in the whole Kingdom of Thailand in 2013 was 25,194 baht ( $£ 477$ or $\$ 746)$ [97]. The expenditure for one full time student at faculty of pharmacy of a public university was 140,000 baht per year $(£ 2,700$ or $\$ 4,100)$ [98]. The proposed increased average cost to cover the additional one year in the PharmD programme was $600,000,000$ baht ( $£ 11,590,000$ or $\$ 17,780,000)$ [48]. Some parents in this study and others reported concerns about the cost of pharmacy education, which can be a major financial investment. However, they were prepared to support their students or seek other financial support such as grants, scholarships or government-sponsored student loan schemes [99-101]. Some academic staff were concerned that the increase of an extra year of education would limit the ability of students to start earning an income and might be a burden for students, their families and the government. This study noted the same considerations as another study [100, 101], in that the curriculum should be designed to deliver an effective education that is able to produce competent pharmacy graduates while also saving money and time. Some students were concerned about the fact that tuition have increased fees but salaries and available positions have not increased, which was a similar concern in the US [100]. Cain et al. suggested that it is necessary to ensure that excellent students are not deterred from pharmacy education by concerns about insurmountable costs or debt after graduation [100].

There were also concerns about the insufficient quantity and quality of trained preceptors, multidisciplinary learning and practice in training sites, quality assurance, support and recognition from administration, and a preceptor development programme [102, 103].

The Thai and Pakistani PharmD curricula are both different from the US PharmD [37, 104]. They were adapted to meet the country's needs by including clinical tracks and industrial pharmacy tracks. In 2012, the percentages of Thai pharmacists in each sector were as follows: hospital (40\%), pharmacy marketing (22\%), community pharmacy (17\%), pharmaceutical industry (10\%), consumer protection (6\%) and education (5\%) $[5,105]$. Hence, a single pattern pharmacy programme might not be able to produce all of the competencies needed in all of the pharmacy practice areas $[3,5]$. This study found a mismatch between pharmacy graduates' competencies and the requirements of the job market. Competencies required for an industrial pharmacist are completely different from a pharmacist who provides pharmaceutical care in tertiary hospitals or from the community pharmacist who provides home health care and health promotion [23, 37]. It is interesting that most pharmaceutical sciences track graduates appeared to work in the community pharmacy setting. Academics should seriously revise the content and practical experiences in the curriculum to meet the needs of graduates and Thai society $[1,3,106]$. Faculties should coordinate with the various Thai pharmacy associations, such as the Association of Hospital Pharmacy (Thailand), Community Pharmacy Association (Thailand), Thai Industrial Pharmacist Association, and Marketing Pharmacy Association of Thailand to update the competencies required by pharmacy graduates. Faculties must adapt more quickly (their vision, academic workforce planning, providing facilities, preceptor co-development programme, legal considerations affecting pharmacists' roles and responsibilities) to support the needs of society and rapidly changing health care systems $[1,7,39,93,104]$.

This study might be of interest to faculties and policy makers to develop pharmacy curricula and national pharmacy competency standards to produce future pharmacy practitioners and pharmaceutical scientists who are ready to work to deliver high-quality services to patients and the public and also consider national pharmacy workforce planning to propose numbers of prospective pharmacy students in different specialties.

The limitation of this study lies in the volunteer participants. Some informants who were involved in the transition process did not participate in this study. It is unclear whether there are differences in the experience and perceptions of the two groups of informants: those who decided to participate and those who did not participate in this study. The findings might be influenced by some participants' enthusiasm about this transition [107]. However, this study attempted to include a maximum variation of 
participants [65], including those who agree and do not agree with this curriculum change. Another limitation is that the transition to an all-PharmD programme is still at an early stage. The first cohort of "all-PharmD students" graduated in March 2015, so the benefit or merit of this transition in terms of both education and services might not be clearly visible at the time of this study (2013). More prolonged and in-depth study is needed to determine the impact of the transition on students' competencies, professional performance in pharmacy services and the satisfaction of employers and society [107].

\section{Conclusions}

This is the first study of its kind to highlight the issues surrounding the transition to the 6-year PharmD programme in Thailand, which was initiated due to the need for higher levels of competency for the nation's pharmacists. The transition was influenced by many factors (e.g., the global trend towards providing patient care services, cooperation of four pharmacy faculties and the Ministry of Public Health to develop a foundation for clinical pharmacy activities in hospital settings, the US-Thai consortium for the development of pharmacy education, which founded by the PECT, and the establishment of the PCT). Many participants perceived benefits from the new pharmacy curriculum; for example, the PharmD graduates will acquire an advanced pharmacy professional degree, improve pharmacy competencies from generalists to specialists, will be ready to work as pharmacists after graduation, will understand health care teams and will provide a high quality of patient care. However, some participants were concerned regarding the curriculum change, such as regarding the higher costs of a longer period of time for study, the mismatch between the pharmacy graduates' competencies and the job market's needs, the need to consider designing the curriculum to suit pharmacy services in other areas in addition to tertiary care settings (e.g., primary care, community pharmacy, consumer protection), and that the number of graduates in IP-PD might exceed the needs of industry, leading them to pursue career paths in community pharmacy for which they were not well prepared. The most crucial concerns are about the insufficient preceptors and training sites, the lack of practical experience of the faculty members and issues related to separate licenses due to the differences in graduates' specialties. Although most of the respondents accepted the need to go forward to the 6-year PharmD programme, the design of an effective curricular, providing a sufficient number of qualified PharmD preceptors, determining certain competencies of pharmacists in different practices and monitoring the quality of pharmacy education still need to be addressed in this transition stage of pharmacy education in Thailand.

\section{Abbreviations}

DDS: Doctor of Dental Surgery; DVM: Doctor of Veterinary Medicine; FIPEd: International Pharmaceutical Federation Education Development Team; IP-PD: Industrial Pharmacy-PharmD programme; MD: Doctor of Medicine; MoPH: Ministry of Public Health; PC-PD: Pharmaceutical carePharmD programme; PharmD: Doctor of Pharmacy; PECT: The Pharmacy Education Consortium of Thailand; PCT: The Pharmacy Council of Thailand; SAP: Social and Administrative Pharmacy; WHO: The World Health Organization; UNESCO: The United Nations Educational, Scientific and Cultural Organisation; US: The United States of America.

\section{Competing interests}

The authors declare they have no competing interests.

\section{Authors' contributions}

TC conceived the study, conducted the semi-structure interviews, coordination of the study, writing, revision and submission of the manuscript. TC, CA, BY designed the study, data analyses and writing of the manuscript. SM, PY advised on the feasibility of the study, data analyses and writing of the manuscript. All authors read and approved the final manuscript.

\section{Acknowledgements}

The researchers would like to thank the Thai Royal Government for the funds granted to undertake this research and would like to thank all participants for their kind participation. The researchers would like to thank Assist.Prof.Dr. Mayuree Tangkiatkumjai, Mrs. Aporn Jaturapatarawong for their valuable recommendations on the data analyses.

\section{Author details}

${ }^{1}$ School of Pharmacy, University of Nottingham, Nottingham, UK. ${ }^{2}$ School of Pharmacy, Faculty of Science, University of Nottingham Malaysia Campus, Semenyih, Selangor Darul Ehsan, Malaysia. ${ }^{3}$ Faculty of Pharmaceutical Sciences, Prince of Songkla University, Hat Yai, Songkhla, Thailand. ${ }^{4}$ Faculty of Pharmaceutical Sciences, Ubon Ratchathani University, Warin Chamrap, Ubon Ratchathani, Thailand.

Received: 28 June 2015 Accepted: 22 October 2015

Published online: 19 November 2015

\section{References}

1. Anderson C, Bates I, Brock T, Brown AN, Bruno A, Futter B, et al. Needs-based education in the context of globalization. Am J Pharm Educ. 2012;76(4):56.

2. Rouse M, Meštrovic A. Quality assurance of pharmacy education: the FIP Global Framework. The Hague, The Netherlands: International Pharmaceutical Federation (FIP); 2014.

3. Anderson C, Futter B. PharmD or needs based education: which comes first? Am J Pharm Educ. 2009;73(5):92.

4. FIP. 2012 FIP Global Pharmacy: Workforce report. International Pharmaceutical Federation (FIP), The Hague, The Natherlands. 2012. URL: www.fip.org/static/ fipeducation/2012/FIP-Workforce-Report-2012/?page=hr2012. Accessed December 102013.

5. Manasse HR. Perpectives on the global evolution and development of pharmacy. Am J Health-Syst Pharm. 2013;70(8):675-9.

6. Anderson C, Bates I, Futter B, Gal D, Rouse M, Whitmarsh S. Global perspectives of pharmacy education and practice. World Med \& Health Policy. 2010;2(1):2.

7. Frankel G, Louizos C, Austin Z. Canadian educational approaches for the advancement of pharmacy practice. Am J Pharm Educ. 2014;78(7):143.

8. Yoo S, Song S, Lee S, Kwon K, Kim E. Addressing the academic gap between 4- and 6-year pharmacy programs in South Korea. Am J Pharm Educ. 2014;78(8):149.

9. Austin Z, Ensom MHH. Education of Pharmacists in Canada. Am J Pharm Educ. 2008;72(6):128.

10. Kishi DT. Japanese pharmaceutical education: impications for Americans teaching Japanese pharmacy students. Am J Health Syst Pharm. 2001;58(11):1032-5.

11. Lin $Y-Y$. Evolution of Pharm D education and patient service in the USA. J Exp Clin Med. 2012;4(4):227-30.

12. Amir M. The after effects of implementing the PharmD degree in developing countries. Am J Pharm Educ. 2011;75(6):124. Letter.

13. Jamshed S, Babar ZUD, Masood I. The PharmD degree in developing countries. Am J Pharm Educ. 2007;71(6):125. Letter. 
14. Ghayur MN. Pharmacy education in developing countries: need for a change. Am J Pharm Educ. 2008;72(4):94.

15. Thomas D, Paul MC, Sumitha C. Genesis and development of pharmacy education and Pharm D in Asia. Int J Pharm Ther. 2011;2(2):61-7.

16. Ahmed SI, Hassali MAA. The controversy of PharmD degree. Am J Pharm Educ. 2008;72(3):71. Letter.

17. Pramyothin P. Archives of 100 years Pharmacy Profession. Bangkok: Pharmacy for society foundation (PSF); 2013.

18. Pongcharoensuk P, Prakongpan S. Centennial pharmacy education in Thailand. J Asian Assoc Schools Pharm. 2012;1(1):8-15.

19. Kapol N, Maitreemit P, Pongcharoensuk P, Armstrong E. Evaluation of curricula content based on Thai pharmacy competency standards. Am J Pharm Educ. 2008;72(1):9.

20. Sonthisombat P. Pharmacy student and preceptor perceptions of preceptor teaching behaviors. Am J Pharm Educ. 2008;72(5):110.

21. Srisopa S, Asuphon O, Montakantikul P. Role of clinical pharmacists for managing infectious diseases in Thailand. J Infect Dis Antimicrob Agents. 2012;29(3):105-12.

22. Keokitichai S. Emerging core curriculum: assertive strategies in pharmacy education, research and practices. FIP's World Congress of Pharmacy and Pharmaceutical Sciences, 31 August - 4 September 2014 Bangkok, Thailand: 2014.

23. Sumpradit N, Suttajit S, Hunnangkul S, Wisaijohn T, Putthasri W. Comparison of self-reported professional competency across pharmacy education programs: a survey of Thai pharmacy graduates enrolled in the public service program. Adv Med Educ Pract. 2014;5:347-57.

24. The past, current status and future trends of pharmacy education in Thailand. In: Tassaneeyakul W, Suthisisang C, Paeratakul O, Sornlertlamvanich K, Napaporn J, Kongkaew C, editors. The General Assembly of Thai Pharmacy to Mark 100 Years of Pharmaceutical Practice and Studies in Thailand; Bangkok, Thailand 2013.

25. Faculty of Pharmacy Mahidol University. Brief History of Pharmacy Education in Thailand. 2013. URL: www.pharmacy.mahidol.ac.th/eng/aboutus.php. Accessed March 142014

26. Nawanopparatsakul S, Keokitichai S, Wiyakarn S, Chantaraskul C. Challenges of pharmacy education in Thailand. Silpakorn University International Journal. 2009-2010; 9-10:19-39.

27. The Royal Thai Government Gazette. The Medical Professions Act of 1936. 1937. URL: www.ratchakitcha.soc.go.th/DATA/PDF/2480/A/160.PDF. Accessed 06 March 2014.

28. The Royal Thai Government Gazette Vol 125 SPN, dated $3^{\text {rd }}$ April. The Pharmacy Council of Thailand's regulation about accredited pharmacy degree 2008. URL: www.pharmacycouncil.org/share/file/file_269.pdf. Accessed March 122014.

29. Pitaknitinun $K$, Jongsirilerd $P$. The coorperation project of the development and establish of curriculum of Master degree in clinical pharmacy in module system by Faculty of Pharmaceutical Sciences, Khon Kaen University, Chiangmai Univeristy, Silpakorn Univesity and Prince of Songkla University and Bureau of Health Service System Development, Department of Health Service Support. Ministry of Public Health. IJPS. 2008;4(2):1-12.

30. Pramyothin P, Sripanidkulchai B, Thirawarapan S, Khunkitti W. Strategies for managing pharmacy education in next two decades: Ministry of University Affairs, Thailand 1999.

31. College of Pharmacy University of Minnesota. Around the Globe: U.S.-Thai consortium helps improve pharmacy education in Thailand. Pharmacy Record. 2011.

32. Millard WJ, Kemp D. U.S.-Thai consortium activities. In: Office of research and graduate studies 2004-2005 Annual report. Florida: College of Pharmacy, University of Florida; 2005.

33. Sakolchai S. Challenging issues for higher education: How do Thai schools of pharmacy prepare themselves? 2004 US-Thai consortium meeting: A celebration of a decade of collaboration. Chicago, Illinois: US-Thai consortium: 2004.

34. Srichana T. Overview of the activites of US-Thai consortium on pharmacy education. 2012.

35. Sripanidkulchai B. U.S.-Thai consortium and development of pharmacy education in Thailand. In: American Association of Colleges of Pharmacy (AACP) meeting. Chicago: American Association of Colleges of Pharmacy; 2008.

36. Titwan A. Pharmacy education in Thailand: past-present-future. 2004 US-Thai consortium meeting: A celebration of a decade of collaboration. Chicago, Illinois: US-Thai consortium; 2004.
37. Chanakit T, Low BY, Wongpoowarak P, Moolasarn S, Anderson C. A survey of pharmacy education in Thailand. Am J Pharm Educ. 2014;78(9):161.

38. Matichon. Pharmacy curriculum change to a six-year programme across Thailand start from 2009. Matichon. 2007; p. 27.

39. Hill DS. The "Entry-Level" Doctor of Pharmacy (Pharm.D.) Degree Issue for Schools of Pharmacy in Canada. Association of Faculties of Pharmacy of Canada: Background Paper; 1999.

40. Carroll NV, Erwin WG, Beaman MA. A Comparison of practice patterns and job satisfaction of California and non-California PharmD graduates: Some implications for the entry level PharmD issue. Am J Pharm Educ. 1984;48(3):236-8.

41. Koda-Kimble M, Herfindal E, Shimomura S, Adler D, Bernstein L. Practice patterns, attitudes, and activities of University of California Pharm.D. graduates. Am J Hosp Pharm. 1985;42(11):2463-71.

42. Ried L, McGhan W. PharmD or BS: Does the degree really make a difference in pharmacists' job satisfaction. Am J Pharm Educ. 1986;50(1):1-5.

43. Barnett C, Matthews H. Practice patterns of BS, postbaccalaureate PharmD and entry-level PharmD graduates of one school of pharmacy. Am J Pharm Educ. 1992;56(4):367-73.

44. Fjortoft N, Lee M. Comparison of activities and attitudes of baccalaureate level and entry-level doctor of pharmacy graduates of the University of Illinois at Chicago. Ann Pharmacother. 1995;29:977-82.

45. Koleba T, Marin JG, Jewesson PJ. Entry-level PharmD degree programs in Canada: some facts and stakeholder opinions. Can Pharm J. 2006;139(6):42-50.

46. Mort JR, Houglum JE, Kaatz B. Use of Outcomes in the Development of an Entry Level PharmD Curriculum. Am J Pharm Ed. 1995;59:327-33.

47. Wongpoowarak P, Sitaruno S, Puttarak P, La-ongkaew S, editors. Stakeholders satisfaction toward the PharmD graduates of Faculty of Pharmaceutical Sciences, Prince of Songkla University. Southern Pharmacy Symposium 2013; Prince of Songkhla University International Convention Centre, Prince of Songkla University.

48. PharmaCafe.com. The Pharmacy Council will have policy for all 6 year PharmD programme; 2008. URL: www.pharmacafe.com/board/ viewtopic.php?f=31\&t=19702\&start=180. Accessed 23 April 2014) [in Thai].

49. ASTV Manager Online. Pharmacy oppose the transition to a six-year pharmacy curriculum. ASTV Manager Online2009.

50. The Pharmacy Council of Thailand. The core pharmacy course structure guideline. 2012. URL: www.pharmacycouncil.org/share/file/file_193.pdf. Accessed October 102013.

51. Anderson C. Education trends, innovations and transformations - case studies. In: Bruno A, editor. 2013 FIDEd Global Education Report. The Natherlands: International Pharmaceutical Federation (FIP); 2013. p. 24-33.

52. The Pharmacy Council of Thailand. Competency in industrial pharmacy. The Pharmacy Council of Thailand. 2013. URL: www.pharmacycouncil.org/share/ file/file_469.pdf. Accessed 20 March 2014.

53. The Pharmacy Council of Thailand. Thai Pharmacy Competency Standards. The Pharmacy Council of Thailand. 2012. URL: www.pharmacycouncil.org/ share/file/file_195.pdf. Accessed 20 March 2014.

54. Bates I, Bruno A, Arakawa N. Global education description: 2013 FIPEd Global Education Report. In: 2013 FIPEd Global Education Report. International Pharmaceutical Federation, The Natherlands. 2013. URL: www.fip.org/files/fip/ FIPEd_Global_Education_Report 2013.pdf. Accessed March 062014.

55. Hoat LN, Viet NL, Wilt G, Broerse J, Ruitenberg E, Wright E. Motivation of university and non-university stakeholders to change medical education in Vietnam. BMC Med Educ. 2009;9:49.

56. Anderson C, Brock T, Bates I, Rouse M, Marriott J, Manasse H, et al. Transforming Health Professional Education. Am J Pharm Educ. 2011;75:2.

57. Kirschenbaum HL, Brown ME, Kalis MM. Programmatic curricular outcomes assessment at colleges and schools of pharmacy in the United States and Puerto Rico. Am J Pharm Educ. 2006;70(1):8.

58. MacCarrick G. Curriculum reform: a narrated journey. Med Educ. 2009;43:979-88.

59. Hinton L, Kurinczuk JJ, Ziebland S. Reassured or fobbed off? Perspectives on infertility consultations in primary care: a qualitative study. Br J Gen Pract. 2012;62(599):e438-45.

60. Harvey J, Avery AJ, Ashcroft D, Boyd M, Phipps DL, Barber N. Exploring safety systems for dispensing in community pharmacies: focusing on how staff relate to organizational components. Res Social Adm Pharm. 2015;11(2):216-27.

61. Guion LA. Triangulation: establishing the validity of qualitative studies. Department of Family, Youth and Community Sciences, Florida Cooperative Extension Service, Institute of Food and Agricultural Sciences, University of Florida. 2002. URL: www.rayman-bacchus.net/uploads/documents/ Triangulation.pdf. Accessed 10 September 2015. 
62. Creswell JW. Qualitative Inquiry and Research Design: Choosing Among Five Approaches. Thousand Oaks, CA: SAGE publications, Inc; 2013.

63. Illing JC, Morrow GM, Kergon CRRn, Burford BC, Baldauf BK, Davies CL et al. Perceptions of UK medical graduates' perparedness for practice: a multi-centre qualitative study reflecting the importance of learning on the job. BMC Med Educ. 2013;13(34). doi:10.1186/1472-6920-13-34.

64. Hinton L, Locock L, Knight M. Maternal critical care: what can we learn from patient experience? A qualitative study. BMJ Open. 2015;5(4):e006676. doi:10.1136/bmjopen-2014-006676.

65. Hinton L, Locock L, Knight M. Partner experiences of "Near-Miss" events in pregnancy and childbirth in the UK: a qualitative study. PLOS ONE. 2014;9(4):e91735.

66. Glaser BG, Strauss AL. The discovery of grounded theory: strategies for qualitative research. London: AldineTransaction; 1967.

67. Charmaz K. Constructing grounded theory: a practical guide through qualitative analysis. London: SAGE Publications Ltd; 2006.

68. Flick U. An introduction to qualitative research. London: Sage Publications Ltd; 2009.

69. Lee ML, Hassali MA, Shafie AA. A qualitative exploration of the reasons for the discontinuation of smoking cessation treatment among quit smoking clinics' defaulters and health care providers in Malaysia. Res Social Adm Pharm. 2013;9(4):405-18.

70. Corden A, Sainsbury R. Using verbatim quotations in reporting qualitative social research: researchers' views. Social policy research unit: University of York; 2006.

71. Lincoln YS, Guba EG. Naturalistic inquiry. Newbury Park: Sage Publications; 1985.

72. Guba EG. ERIC/ECTJ Annual Review Paper: Criteria for asessing the trustworthiness of naturalistic inquiries. Educational Communication and Technology. 1981;29(2):75-91.

73. Gill PJ, Hislop J, Mant D, Harnden A. General practitioners' views on quality markers for children in UK primary care: a qualitative study. BMC Family Practice 2012; 13(92). doi:10.1186/1471-2296-13-92.

74. Larson ML. Meaning-based translation: a guide to cross-language equivalence. 2nd ed. New York: University Press of American, Inc.; 1998.

75. Chen $\mathrm{H}$, Boore JR. Translation and back-translation in qualitative nursing research: methodological review. J Clin Nurs. 2010;19(1-2):234-9.

76. Squires $A$. Methodological challenges in cross-language qualitative research: a research review. Int J Nurs Stud. 2009;46(2):277-87. doi:10.1016/ j.ijnurstu.2008.08.006

77. Kamarudin G, Penm J, Chaar B, Moles R. Preparing hospital pharmacists to prescribe: stakeholders' views of postgraduate courses. Int J Pharm Pract. 2013;21(4):243-51.

78. Fereday J, Muir-Cochrane E. Demonstrating rigor using thematic analysis: a hybrid approach of inductive and deductive coding and theme development. International Journal of Qualitative Methods. 2006;5(1):80-92.

79. Whiteley A. Grouned research: A modified grounded theory for the business setting. Graduate School of Business Working Paper Series: no.19. Curtin University of Technology, Graduate School of Business; 2000.

80. Saleh AM, Shabila NP, Dabbagh AA, Al-Tawil NG, Al-Hadithi TS. A qualitative assessment of faculty perspectives of small group teaching experience in Iraq. BMC Med Educ. 2015;15(19). doi:10.1186/s12909-015-0304-7.

81. Latif A, Boardman HF, Pollock K. A qualitative study exploring the impact and consequence of the medicines use review service on pharmacy support-staff. Pharm Pract (Granada). 2013;11(2):118-24.

82. Payakachat N, Gubbins PO, Ragland D, Norman SE, Flowers SK, Stowe CD, et al. Academic help-seeking behavior among student pharmacists. Am J Pharm Educ. 2013;77(1):7.

83. Guest G, MacQueen KM, Namey EE. Validity and reliability (credibility and dependability) in qualitative research and data analysis. In: Knight V, Habib L, Koscielak K, Virding A, Rosenstein A, editors. Applied thematic analysis. London: Sage Publications; 2012. p. 79-106.

84. Anderson C. Presenting and evaluation qualitative research. Am J Pharm Educ. 2010;74(8):141.

85. Creswell JW. Research design, qualitative, quantitative, and mixed methods approaches. Thousand Oaks: Sage; 2003.

86. Braun V, Clarke V. Using thematic analysis in psychology. Qualitative Research in Psychology. 2008;3(2):77-101.

87. Ziebland S, McPherson A. Making sense of qualitative data analysis: an introduction with illustrations from DIPEX (personal experiences of health and illness). Med Educ. 2006;40:405-14.
88. Strauss AL, Corbin JM. Basics of qualitative research: Grounded theory procedures and techniques. Newbury Park: Sage Publications; 1990.

89. Dolder C, Nakagawa S, Sakamaki A. Changes in Japanese pharmacy education and practice. Am J Health-Syst Pharm. 2008;65(3):201-2. Letter.

90. Raman-Wilms L. Evolution in pharmacy education: developing effective patient care practitioners. Can J Hosp Pharm. 2012;65(4):253-7.

91. American Association of Colleges of Pharmacy. Commission to implement change in pharmaceutical education. American Association of Colleges of Pharmacy (AACP). 2013. URL: www.aacp.org/resources/historicaldocuments/ Documents/COMMISSPOSPAPER3.pdf. Accessed December 012013.

92. Kim E, Ghimire S. Career perspectives of future graduates of the newly implemented 6-year pharmacy educational system in South Korea. Am J Pharm Educ. 2013;77(2):37. Letters.

93. Knapp DA. The rocky road to educational change: adopting the entry-level PharmD at Maryland, 1989-93. J Am Pharm Assoc. 2011;51(6):692-701.

94. Janke KK, Traynor AP, Boyle CJ. Competencies for student leadership development in Doctor of Pharmacy curricula to assist curriculum committees and leadership instructors. Am J Pharm Educ. 2013;77(10):222.

95. Ngorsuraches S, Chaibu B. Pharmacist compensation survey in Thailand. Thai J Pharm Sci. 2004;28(3-4):125-34.

96. Aisoonphisarnkul P, Kittisopee T, Sakulbumrungsil R. A needs assessment study of pharmaceutical care curriculum. Thai J Hosp Pharm. 2012;22(2):153-67.

97. National Statistical Office. Average montly income per household: 1996-2013. In: Office NS, editor. Bangkok, Thailand: Ministry of Information and Communication technology; 2013.

98. Clungsombat $M$. The analysis of expenditure per student of Faculty of Pharmaceutical Sciences, Naresuan University in the 2005 fiscal year. Phitsanulok: Faculty of Pharmaceutical Sciences, Naresuan University; 2005.

99. Ziderman A. Student loans in Thailand: are they effective, equitable, sustainable? Bangkok: UNESCO Bangkok: International Institute for Educational Planning; 2003.

100. Cain J, Campbell T, Congdon HB, Hancock K, Kaun M, Lockman PR, et al. Pharmacy student debt and return on investment of a pharmacy education. Am J Pharm Educ. 2014;78(1):5.

101. Cain J, Campbell T, Congdon HB, Hancock K, Kaun M, Lockman PR, et al. Complex issues affecting student pharmacist debt. Am J Pharm Educ. 2014;78(7):131

102. Danielson J, Craddick K, Eccles D, Kwasnik A, O'Sullivan TA. A qualitative analysis of common concerns about challenges facing pharmacy experiential education programs. Am J Pharm Educ. 2015;79(1):6.

103. Chan TY, Candlish C, Markham A, Worsley A. An analysis of transnational pharmacy education in Asia Pacific Region. Kuala Lumpur, Malaysia: Presentation at the 9th Commonwealth Pharmaceutical Association Conference cum Malaysian Pharmaceutical Society Pharmacy Scientific Conference 2007; 2007.

104. Babar Z, Scahill SL, Akhlaq M, Garg S. A bibliometric review of pharmacy education literature in the context of low-to middle-income countries. Currents Pharm Teach Learn. 2013;5(3):218-32.

105. Prapunwattana M. Thailand pharmacy professional assembly (99 years). Nonthaburi: The Pharmacy Council of Thailand; 2012. p. 60.

106. Anderson C, Bates I, Brock T, Brown A, Bruno A, Gal D, et al. Highlights from the FIPEd Global Education Report. Am J Pharm Educ. 2014;78(1):4.

107. Sherer R, Dong H, Yenfeng Z, Stern S, Jiong Y, Matlin K, et al. Medical education reform in Wuhan University, China: A preliminary report of an international collaboration. Teach Learn Med. 2015;25(2):148-54.

108. Maitreemit P, Pongcharoensuk P, Kapol N, Armstrong EP. Pharmacist perceptions of new competency standards. Pharm Pract (Granada). 2008;6(3):113-20.

109. Hall J. The profession and practice of pharmacy. Pharmacy practice. Oxford: Oxford University Press; 2013.

110. The Pharmacy Education Consortium of Thailand (PECT). The Pharmacy Education Consortium of Thailand:Organization profile 2014. 2014. URL: www.pect.pharmacycouncil.org/?page id=199. Accessed 07 May 2015.

111. Cain J, Noel Z, Smith KM, Romanelli F. Four rights of the pharmacy educational consumer. Am J Pharm Educ. 2014;78(6):115.

112. Why parents play an important role in university life. In: The Independent. 13 August 2006. URL: www.independent.co.uk/news/education/higher/whyparents-play-an-important-role-in-university-life-411868.html. 
113. Harper CE, Sax LJ, Wolf DSS. The role of parents in college students' sociopolical awareness, academic and social development. J Student Affairs Res Pract. 2012;49(2):137-56.

114. Yanchick VA. Multidisciplinary Education: a challenge for pharmacy education. Am J Pharm Educ. 2004;68(3):77.

115. Al-Arifi MN. Patients' perception, views and satisfaction with pharmacists role as health care provider in community pharmacy setting at Riyadh, Saudi Arabia. Saudi Pharm J. 2012;20(4):323-30.

116. Shiyanbola OO, Mort JR. Patients' perceived value of pharmacy quality measures: a mixed-methods study. BMJ Open. 2015;5:e006086.

117. O'Keefe $M$, Jones A. Promoting lay participation in medical school curriculum development: lay and faculty perceptions. Med Educ. 2007:41:130-7.

118. The General Pharmaceutical Council. Public perceptions of pharmacies: Ipsos Public Affairs: The Social Research and Corporate Reputation Specialists. 2014

\section{Submit your next manuscript to BioMed Central and take full advantage of:}

- Convenient online submission

- Thorough peer review

- No space constraints or color figure charges

- Immediate publication on acceptance

- Inclusion in PubMed, CAS, Scopus and Google Scholar

- Research which is freely available for redistribution 